\title{
Competencia entre México y China en el interior del mercado de Estados Unidos ${ }^{1}$
}

\section{Competition between Mexico and China within the market of the United States}

\author{
Maximiliano Gracia-Hernández*
}

\begin{abstract}
The document shows the dynamics of exports from Mexico and China in the U.S. market, it considers the chain of thread-textile-garment to four digits. It discusses the chapters 61, 62 and 63. In 2000 Mexico was an exporter leader in all branches that make up chapters 61 to 63, now only five of the thirty branches analyzed have succeeded in increasing its exports to the U.S. market. We consider a half-truth that the total of branches that make up the Textile Clothing of Mexico cannot compete against China in the EU market; the evidence shows that there are still some branches in which Mexico can.
\end{abstract}

Keywords: textile and clothing industry, international competitiveness, MexicoChina competition.

\begin{abstract}
Resumen
En este artículo se muestra la dinámica que han seguido las exportaciones de México y China en el interior del mercado de Estados Unidos (EU), se considera la cadena hilo-textil-confección a cuatro dígitos, y se analizan los capítulos 61, 62 y 63. En el año 2000 México era un líder en todas las ramas que componen los capítulos 61 a 63, actualmente sólo cinco de las 30 ramas analizadas han logrado incrementar sus exportaciones en el mercado de EU. Consideramos una verdad a medias que el total de ramas que componen la industria textilconfección de México no puedan competir contra China en el mercado de EU, pues la evidencia muestra que aún quedan algunas ramas mexicanas que sí lo pueden hacer.
\end{abstract}

Palabras clave: industria textil-confección, competitividad internacional, competencia México-China.

\footnotetext{
${ }^{1}$ Agradezco los valiosos comentarios de Enrique Dussel Peters, de Gerardo Rodríguez Arias y de dos dictaminadores anónimos.

* El Colegio del Estado de Hidalgo y Universidad La Salle, Pachuca. Correo-e: maximiliano@ elcolegiodehidalgo.edu.mx, graciamaximiliano@hotmail.com.
} 


\section{Introducción}

La importancia al analizar la industria textil-confección (ITC) se basa en que la distribución mundial de su producción y de su comercio ha cambiado en los últimos ańos, pues es uno de los sectores que más se ha globalizado. Entre los años cincuenta y ochenta la industria de la confección se concentraba en los países industrializados, posteriormente -con el propósito de aprovechar los bajos salarios- el proceso de ensamble de ropa se trasladó a los países subdesarrollados. Los países receptores fomentaron la llegada de inversiones mediante cambios en sus regulaciones nacionales (zonas francas en países del Caribe, en el sudeste asiático y la existencia del régimen de maquilas en México), con ello disminuyó la actividad en la mayoría de los países industrializados. Sin embargo la casa matriz y la producción con tecnología avanzada se quedó en las naciones industrializadas.

Otro elemento que lleva al análisis y reflexión acerca de la ITC estriba en su importancia, ya que es uno de los sectores manufactureros que genera más empleo no calificado. Aunado a lo anterior, la industria de la confección por medio de la maquila hecha en casa crea oportunidades para segmentos pobres de la población que tienen pocas opciones de empleo.

En diversos textos se muestra la caída de las exportaciones de México en el mercado de EU y el reposicionamiento de la República Popular China (China, en adelante). En particular, la importancia del trabajo estriba en que aporta nueva evidencia en un campo hasta ahora poco explorado y que reviste gran trascendencia para México, sobre todo porque la ITC tiene fuerte presencia regional y genera muchos empleos. Asimismo, son pocos los estudios que profundicen en análisis por cadenas y que a la vez comparen las dos economías como rivales en un mercado.

China es un país que está de moda en la esfera económica internacional; en diversas investigaciones (Chávez y Leyva, 2007: 942; Vázquez, 2002: 81-82) se afirma que en el mercado de Estados Unidos (EU) México está perdiendo participación y China la está ganando ${ }^{2}$ lo cual consideramos que es una verdad a medias.

Estamos ciertos de que México está siendo desplazado por la economía China como el principal proveedor de mercancías en el mercado de EU; sin embargo México tiene ramas ${ }^{3}$ en las cuales es altamente competitivo, pero para continuar así requiere apoyos sistémicos que le permitan a dichos segmentos hacerle frente en el mercado de $\mathrm{EU}$ a los productos originarios

${ }^{2}$ Las manufacturas representan más de $99 \%$ del total exportado por China al mercado de EU.

${ }^{3}$ En los cuadros del Anexo estadístico se mencionan los productos que corresponden a cada rama. 
de China. Uno de esos segmentos se ubica en la cadena textil-confección, en particular en los capítulos señalados.

El periodo de análisis abarca de 2000 a 2008, el primer ańo se considera importante para la investigación dado que en ese entonces se empieza a observar una desviación entre los montos exportados por China y México al mercado de EU.

El trabajo considera el análisis a cuatro dígitos de la cadena hilotextil-confección, ${ }^{4}$ se estudian únicamente los capítulos $61,{ }^{5} 62^{6}$ y $63 ; 7^{7}$ la razón es que estos tres capítulos representan en la segunda división ${ }^{8}$ manufacturera, $80.4 \%$ del total exportado por México al mercado del país del norte.

\footnotetext{
${ }^{4}$ Esta cadena va más allá de los capítulos 61 a 63, implica más de 5,000 fracciones a 10 dígitos del Sistema Armonizado.

${ }^{5}$ Del capítulo 61, la rama 6101 corresponde a abrigos, chaquetones, capas, anoraks, cazadoras
} y artículos similares, de punto, para hombres o niños (excepto los artículos de la partida 6103); la 6102 corresponde a abrigos, chaquetones, capas, anoraks, cazadoras y artículos similares, de punto, para mujeres o nińas (excepto los artículos de la partida 6104); la 6104, trajes sastre, conjuntos, chaquetas (sacos), vestidos, faldas, faldas pantalón, pantalones largos, pantalones con peto, pantalones cortos (calzones) y shorts (excepto de bańo), de punto, para mujeres o niñas; la 6107 incluye calzoncillos, incluidos los largos y los slips, camisones, piyamas, albornoces, batas de casa y artículos similares, de punto, para hombres o niños; la 6108 incluye combinaciones, enaguas, bragas (bombachas, calzones), incluso las que no llegan hasta la cintura, camisones, piyamas, saltos de cama, albornoces, batas de casa y artículos similares, de punto, para mujeres o nińas; la rama 6110 corresponde a suéteres (jerseys), pullovers, cárdigans, chalecos y artículos similares de punto; la 6111 corresponde a prendas y complementos (accesorios) de vestir, de punto, para bebés; la 6115 calzas, pantimedias, leotardos, medias, calcetines y demás artículos de calcetería, incluso de compresión progresiva (por ejemplo, medias para varices), de punto; la 6116, guantes, mitones y manoplas, de punto; la 6119, tshirts y camisetas interiores de punto.

${ }^{6}$ El capítulo 62 corresponde a prendas y complementos (accesorios) de vestir, excepto los de punto. Donde la rama 6203 incluye trajes (ambos o ternos), conjuntos, chaquetas, pantalones largos, pantalones con peto, pantalones cortos (calzones) y shorts (excepto de baño), para hombres o niños; la 6204, trajes sastre, conjuntos, chaquetas, vestidos, faldas, faldas pantalón, pantalones largos, pantalones con peto, pantalones cortos (calzones) y shorts (excepto de baño), para mujeres o niñas; la 6211, conjuntos de abrigo para entrenamiento o deporte (chandales), monos (overoles) y conjuntos de esquí y bañadores; las demás prendas de vestir; la 6210, prendas de vestir confeccionadas con productos de las partidas 5602, 5603, 5903, 5906, 5907; la 6205, camisas para hombres o nińos; la 6201, abrigos, chaquetones, capas, anoraks, cazadoras y artículos similares, para hombres o niños (excepto los artículos de la partida 6203); la 6212, sostenes (corpiños), fajas, corsés, tirantes (tiradores), ligas y artículos similares, y sus partes, incluso de punto; la 6206, camisas, blusas y blusas camiseras, para mujeres o nińas; la 6202, abrigos, chaquetones, capas, anoraks, cazadoras y artículos similares, para mujeres o nińas (excepto los artículos de la partida 6204).

${ }^{7}$ Del capítulo 63 que incluye los demás artículos textiles confeccionados, juegos, prenderías y trapos; la rama 6303 corresponde a visillos y cortinas, guardamalletas y rodapiés de cama; la 6305, sacos (bolsas) y talegas para envasar; la 6302 corresponde a ropa de cama, de mesa, de tocador o cocina; la 6304, artículos de tapicería (excepto los de la partida 9404); la rama 6307 corresponde a los demás artículos confeccionados, incluidos los patrones para prendas de vestir; la 6310 corresponde a trapos, cordeles, cuerdas y cordajes, de materia textil, en desperdicios o en artículos inservibles; la 6301 corresponde a mantas; la 6306 a toldos de cualquier clase, tiendas (carpas), velas para embarcaciones, deslizadores o vehículos terrestres, así como artículos de campamento.

${ }^{8}$ Incluye textiles, prendas de vestir e industria del cuero. 
El objetivo de esta investigación es determinar si dentro de la cadena textil-confección, en particular en los capítulos de referencia, existe competencia entre México y China en el mercado de Estados Unidos.

En este trabajo se utiliza el método deductivo que va de lo general a lo particular. Está organizado en cinco secciones: la primera ofrece, a partir del Informe Global de Competitividad (IGC), un marco general de la situación actual de la competitividad en México y China en el entorno mundial. La segunda presenta algunas transformaciones que generó a la ITC la firma del Acuerdo Multifibras y algunos efectos en la ITC cuando se liberalizó el comercio. En la tercera se muestra la participación de México, China y EU en el mercado mundial de textiles y confección. La cuarta sección revisa la competencia entre México y China en el mercado de EU, particulariza primero en los capítulos 61 a 63 del sistema armonizado y, posteriormente, en las ramas que componen cada uno de los capítulos señalados. Por último, la quinta sección presenta las ventajas, oportunidades, desventajas y amenazas que tiene la ITC de México y China para exportar a EU.

\section{La competitividad de México y China}

China sorprende al mundo entero por sus variables macroeconómicas, por ello consideramos que en corto tiempo será la gran potencia mundial como lo fue Holanda en el siglo XviII, Inglaterra en el XIX y Estados Unidos en el xx.

Entre los años 2000 y 2009 (septiembre) China logró generar un crecimiento del PIB real anual promedio de 9.5\%, dato superior al del resto de las economías capitalistas; se ubicó como el segundo proveedor de mercancías en el mercado de Estados Unidos, participó con 357,000 millones de dólares, lo que representó $16.4 \%$ del total de mercancías importadas por dicho país. La base de la economía China es sobre todo industrial y de servicios, sectores que participaron con 89\% del PIB; el ahorro fue equivalente a $49 \%$ del PIB; la formación bruta del capital representó 44\% del PIB, y las exportaciones participaron con 41\% del pIB.

Con base en el Informe Global de Competitividad (IGC) 2009-2010, México se ubicó en el lugar 60 (se evaluaron 133 economías). Se mostró que México no ha mejorado su nivel de competitividad en relación con el año precedente (2008-2009). Más aún, México perdió ocho posiciones dentro del índice. ${ }^{9}$ De acuerdo con la misma fuente, China se ubicó en el IGC en el lugar 29; a diferencia de México, China mejoró su nivel de

\footnotetext{
${ }^{9}$ En 2009-2010 México se ubicó en el lugar 60; en 2008-2009 (de 134 países) se encontraba posicionado en el mismo lugar, pero en 2007-2008 (de 131 países) se encontraba en el lugar 52, esto es, en sólo dos años México perdió ocho lugares dentro del ranking mundial de competitividad.
} 
competitividad en relación con años anteriores ${ }^{10}$ En sólo dos años China ganó cinco posiciones dentro del ranking mundial de competitividad, en contraste, México en el mismo periodo perdió ocho posiciones.

Si consideramos los 12 pilares básicos (Anexo, cuadros 1a-c) observamos que México es menos competitivo que China. En estos 12 pilares México está mejor posicionado únicamente en sofisticación del mercado financiero y en preparación tecnológica. ${ }^{11}$ Para el segundo punto, Dutta (2005: 16) considera que no será por mucho tiempo, China requiere un corto plazo para superar a México en ese pilar, y es que China está en un proceso de rápida evolución dentro de la revolución tecnológica mundial. Aunado a lo anterior, México tiene una serie de factores problemáticos para hacer negocios: burocracia ineficiente, corrupción, delincuencia, falta de acceso al financiamiento, regulaciones laborales restrictivas, soporte inadecuado en infraestructura, entre otros (cuadro 2).

$\mathrm{Al}$ revisar algunos datos comparativos entre México y China se observan asimetrías en las dos economías. Con datos del año 2008, en el cuadro 3 se comparan cuatro variables importantes de los dos países: México es superior únicamente en la variable PIB per cápita, México se ubica por abajo de China en población total, PIB y participación del PIB en el total mundial. Cabe señalar que China -con excepción de la variable Рів per cápita- es una potencia que se sitúa en los tres primeros lugares mundiales.

Mejorar la productividad permite a cualquier economía competir con efectividad en el mercado mundial. Mientras México ha perdido competitividad, China la ha ganado, por lo que se debe destacar la necesidad que tiene México de emprender una verdadera reforma competitiva, cuya primer tarea debe ser detectar los factores que impiden la competitividad, para después poner en marcha las tareas pertinentes.

\section{Del Acuerdo Multifibras a la OMC}

Con la presión de los países desarrollados, en $1974^{12}$ surgió el Acuerdo Multifibras (AMF) que permitió imponer regímenes de cuotas de impor-

${ }^{10}$ En 2009-2010 China se encuentra en el lugar 29; en 2008-2009 (de 134 países) estaba en el lugar 30, pero en 2007-2008 (de 131 países) se ubicaba en la posición 34.

${ }^{11}$ El pilar de referencia incluye: disponibilidad de las últimas tecnologías, absorción de tecnología, leyes relacionadas con las nuevas tecnologías, la IED y la transferencia de tecnología, las suscripciones de telefonía celular, el número de usuarios de Internet, el número de computadoras personales y de suscriptores de banda ancha de Internet.

${ }^{12}$ Para el caso de EU deben verse las normas arancelarias fracción 807.30 de 1956 y fracción 807.00 de 1963. A principios de los ańos sesenta aparece el régimen arancelario estadounidense: la fracción 9802.00.80 (conocida como Ley 807). Esta Ley tasa importaciones considerando solamente el valor agregado en el país productor si los componentes se importan de Estados Unidos. 
tación ${ }^{13}$ para países productores, combinado con tarifas arancelarias, el objetivo fue hacer frente a la competencia de los países productoresexportadores del Pacífico asiático.

El AMF fue suscrito por 41 países, posteriormente se renovó en 1977, 1981, 1986 y 1991. En la conclusión de la Ronda Uruguay del GATT se acordó que a partir del 1 de enero de 1995 se remplazara por el Acuerdo sobre los Textiles y el Vestido (ATV) de la OMC, que establecía un proceso de transición de 10 años para la supresión definitiva de los contingentes. La fecha final fue el 1 de enero de 2005, año a partir del cual los países importadores no pudieron discriminar a los exportadores, entre ellos a China; el propio ATV dejó de existir. En esencia, el Acuerdo abarcó todos los textiles y prendas de vestir definidos en los capítulos 50 a 63 del Sistema Armonizado de Designación y Codificación de Mercancías (Sanjay et al., 2001: 5-6).

Es importante destacar que Estados Unidos otorgó a China el tratamiento de nación más favorecida a partir del ingreso de ese país a la OMC, lo que le permitió aprovechar sus ventajas para aumentar sus exportaciones de prendas de vestir a Estados Unidos.

Con base en diversos modelos y metodologías, Dussel y Liu (2004: 36) presenta algunas estimaciones de los principales efectos que generó China en la ITC mundial:

- Existen coincidencias de que el principal sector beneficiado con la adhesión de China a la OMC será el de prendas de vestir de ese país. Para el caso de los textiles y con objeto de aumentar las exportaciones de prendas de vestir, se esperan importantes incrementos en las importaciones de insumos.

- Los efectos para China serán particularmente importantes y positivos en los productos intensivos en fuerza de trabajo, como textiles y confección, juguetes, cuero y calzado (Lanchovichina y Martin, 2003: 15-20; OCDE, 2002: 17) ${ }^{14}$ En la mayor parte de estos modelos se concluye que México será el principal perdedor en términos de PIB y exportaciones, mientras China resultará beneficiada en la cadena hilo-textil-confección (François y Spianger, 2002: 10).

${ }^{13} \mathrm{El}$ antecedente de las cuotas se remonta a los acuerdos impuestos por los grandes países que aplicaban de manera unilateral cuotas a los países productores con capacidad de competir en los grandes mercados. Las prendas de vestir fue uno de los sectores más afectados.

${ }^{14}$ Yongzheng Yang (2003), con base en el modelo Global Trade Analysis Project (GTAP) desarrollado por el FMI, estima que el CAFTA podría tener un efecto positivo de $1.5 \%$ en el PIB regional, y particularmente por el aumento en las exportaciones a EU de prendas de vestir; sin embargo, al considerar la liberalización de las cuotas en 2005, el efecto positivo disminuye sustancialmente, ya que estima que las exportaciones sólo aumentarían a la mitad de lo previsto. Con el ingreso de China a la oмc, Yang estima que América Latina será el principal perdedor en el rubro de prendas de vestir, calculando una pérdida en sus exportaciones de $32.2 \%$ hasta 2006. 
Según las más recientes estimaciones, con la eliminación de cuotas China podría aumentar su participación en el mercado estadounidense entre 16 y $50 \%$, mientras México caería entre 10 y 3\% y el resto de América entre 16 y 5\%; los efectos serán absorbidos principalmente por México, Centroamérica y República Dominicana. Destaca el caso de México, país que tendrá los mayores efectos tanto por la eliminación del ATV como por la liberalización de los servicios (López et al., 2009: 138).

\section{Participación de México, China y Estados Unidos en el mercado mundial de textiles y confección}

Actualmente la ITC se ubica en todo el mundo, se vincula entre sí a través de una extensa red de subcontratación mundial en la que participan unidades de producción de todos los tamaños y de todos los niveles de desarrollo. ${ }^{15}$ En el proceso de producción y distribución tiene gran influencia la empresa multinacional, en cuyo marco los proveedores deben respetar los costos y la flexibilidad que les marca la gran empresa.

\subsection{Industria textil}

\subsubsection{Exportación}

En el año 2008 las exportaciones textiles mundiales ascendieron a 229,000 millones de dólares. La Unión Europea (UE-27) participó con 32.1\%, ${ }^{16}$ China con $26.1 \%$, EU con $5 \%$ y México con $0.8 \%$. Cabe mencionar que durante dicho ańo tan sólo 14 economías exportaron el 100\% del total mundial. China es el segundo exportador en el mundo y México el décimocuarto.

\subsubsection{Importación}

En el mismo año de referencia, la Ue-27 fue el principal importador mundial de textiles, se ubicó en la primera posición con 10.6\% (si se consideran las importaciones dentro de la comunidad, el porcentaje se eleva a $31.9 \%$ ), EU ocupó el segundo lugar con 8.8\%, China participó con $6.2 \%$, México importó $2 \%$, que lo ubicó en la octava posición mundial. Tan sólo 15 economías importaron el 76 por ciento.

15 "Como parte de sus planes de restructuración, entre 1998 y 2002 Levi’s cerró 30 de las 32 plantas de producción y acabados de su propiedad en Estados Unidos [... D Datos para 2007 muestran que en la actualidad la firma no posee ninguna planta de producción en Estados Unidos" (García, 2009: 120).

${ }^{16}$ Exportaciones intra y extracomunitarias, si se excluye el comercio dentro de la comunidad Europa exportó $9.7 \%$ del total mundial. 


\subsubsection{Intercambio comercial}

Para el mercado de EU, China constituye el primer socio comercial; durante 2008 EU importó de dicho país 7,883 mdd, lo que representó $34 \%$ de sus importaciones totales de textiles; mientras que México le exportó 1,500 mdd, que equivale a $6.5 \%$ en ese rubro. Cabe señalar que durante el periodo 2000-2008 las exportaciones textiles de China a EU crecieron 19\%, en contraste las mexicanas descendieron uno por ciento.

\subsection{Industria de la confección}

\subsubsection{Exportaciones}

En la industria de la confección China es el principal exportador de prendas de vestir en el mundo, ${ }^{17}$ sus exportaciones durante 2008 ascendieron a 120,000 millones de dólares, lo que representó 33\% del total mundial vendido. La variación porcentual durante el periodo 2000-2008 fue de 16 por ciento.

En 2008 México exportó 4.9 mil millones de dólares, equivalente a $1.4 \%$ mundial. En contraste con China, en México la variación porcentual anual 2000-2008 tuvo una caída de 7 por ciento.

México y EU han perdido participación en el total exportado mundial de prendas de vestir, de 2000 a 2008 descendieron 7 y 8\%, respectivamente. Por su parte, China ganó mercado e incrementó sus exportaciones en $16 \%$, lo que se puede atribuir principalmente al fin del ATv de la OMC.

\subsubsection{Importaciones}

En 2008 la UE-27 fue el principal importador mundial de confecciones con 178,000 millones de dólares (incluye las importaciones intracomunitarias), EU se mantuvo en el segundo lugar con compras mayores a los 82.5 mil millones de dólares, le sigue en importancia Japón con 26,000 y la Federación Rusa con 20,000. México se ubicó en el décimoprimer sitio con 2.5 mil millones de dólares (cuadro 4).

$\mathrm{Al}$ revisar la situación mundial de los tres capítulos objeto de esta investigación, y su participación en las importaciones de EU, observamos lo siguiente:

- Capítulo 61. A partir del año 2000 Vietnam, Honduras, Indonesia, Pakistán, Camboya e India incrementaron sus exportaciones a ese

${ }^{17}$ Sólo detrás de Ue-27, que exportó al resto del mundo $36.1 \%$ (incluye comercio dentro de Europa; pero si se excluye dicha región, únicamente exportó $7.7 \%$ mundial). 
país, fue el año en que se liberalizó el comercio de textiles y vestido; en contraste, México perdió presencia en el mercado de EU.

- Capítulo 62. A partir de 2003 la brecha entre China y todos los demás países proveedores ${ }^{18}$ de EU se amplió, de manera que no hay posibilidad -al menos en el corto plazo- de competir en volumen exportado con la economía China al mercado de EU.

- Capítulo 63. China es el principal exportador del capítulo 63 en el mercado de EU con 50\% del total mundial; Pakistán e India abastecen 12.4 y $12.2 \%$, respectivamente. México se colocó en el cuarto lugar con una participación de 5.7\%. En el año 2008, mientras Pakistán, India y Tailandia ganaron mercado en EU, México lo perdió (gráfica Ib). Cabe destacar que en el capítulo 63, a diferencia del 61 y 62, México mantiene una constante en las exportaciones a EU (con excepción del año 2008). Los resultados anteriores se acercan a lo señalado por Nordas (2004: 30), quien señala que posterior a la eliminación de cuotas en la industria de la confección, la participación de China en el mercado de EU se incrementaría de 16 a 50\%; México, por el contrario, descendería su participación de 10 a 3 por ciento.

\section{Competencia entre México y China en el mercado de EU}

Para el análisis de la cadena hilo-textil-confección consideramos únicamente los capítulos 61 a 63 del Sistema Armonizado de Designación y Codificación de Mercancías. Según información del INEGi (2007), estos tres capítulos representan $80.4 \%$ del total de las exportaciones mexicanas de la división II manufacturera, ${ }^{19}$ que comprende textiles, prendas de vestir e industria del cuero.

\footnotetext{
${ }^{18}$ Es el caso de países como Bangladesh, Vietnam, Indonesia, India, Sri Lanka, Camboya y Tailandia.

${ }^{19}$ Según el INEGI (2007), en las industrias manufactureras se tienen 21 subsectores de actividad económica: 311 Industria alimentaria; 312 Industria de las bebidas y del tabaco; 313 Fabricación de insumos textiles; 314 Confección de productos textiles, excepto prendas de vestir; 315 Fabricación de prendas de vestir; 316 Fabricación de productos de cuero, piel y materiales sucedáneos, excepto prendas de vestir; 321 Industria de la madera; 322 Industria del papel; 323 Impresión e industrias conexas; 324 Fabricación de productos derivados del petróleo y del carbón; 325 Industria química; 326 Industria del plástico y del hule; 327 Fabricación de productos a base de minerales no metálicos; 331 Industrias metálicas básicas; 332 Fabricación de productos metálicos; 333 Fabricación de maquinaria y equipo; 334 Fabricación de equipo de computación, comunicación, medición, y de otros equipos, componentes y accesorios electrónicos; 335 Fabricación de equipo de generación eléctrica y aparatos y accesorios eléctricos; 336 Fabricación de equipo de transporte; 337 fabricación de muebles y productos relacionados; 339 Otras industrias manufactureras.
} 


\section{Gráfica I}

EU: importaciones del capítulo 61 prendas y complementos (accesorios) de vestir, de punto, 2000-2008 (millones de dólares)

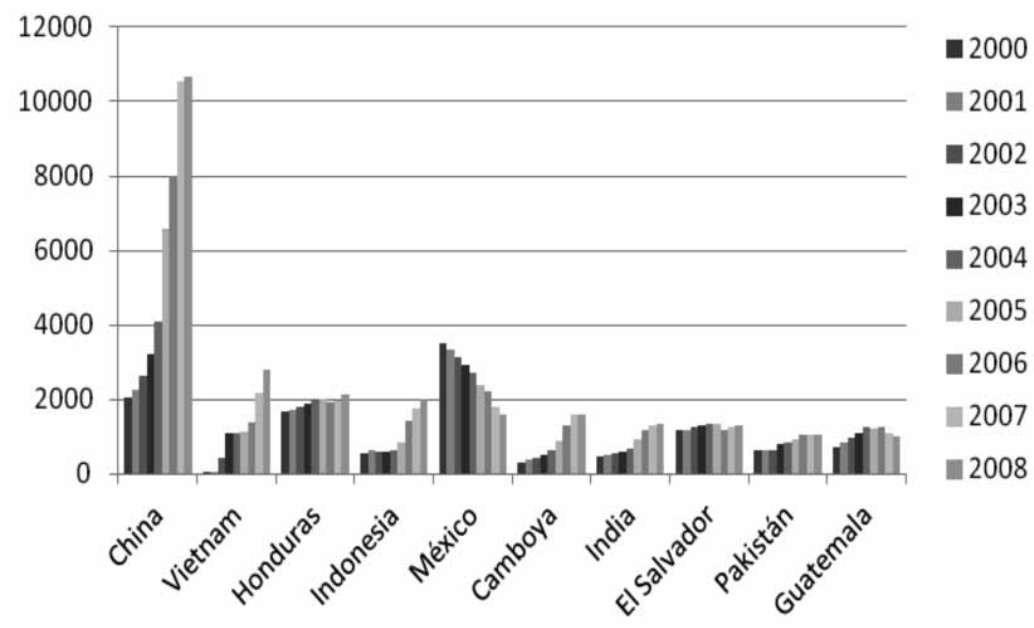

Fuente: Elaboración propia con base en Foreign Trade (2010).

Gráfica Ia

EU: importaciones del capítulo 62

(millones de dólares)

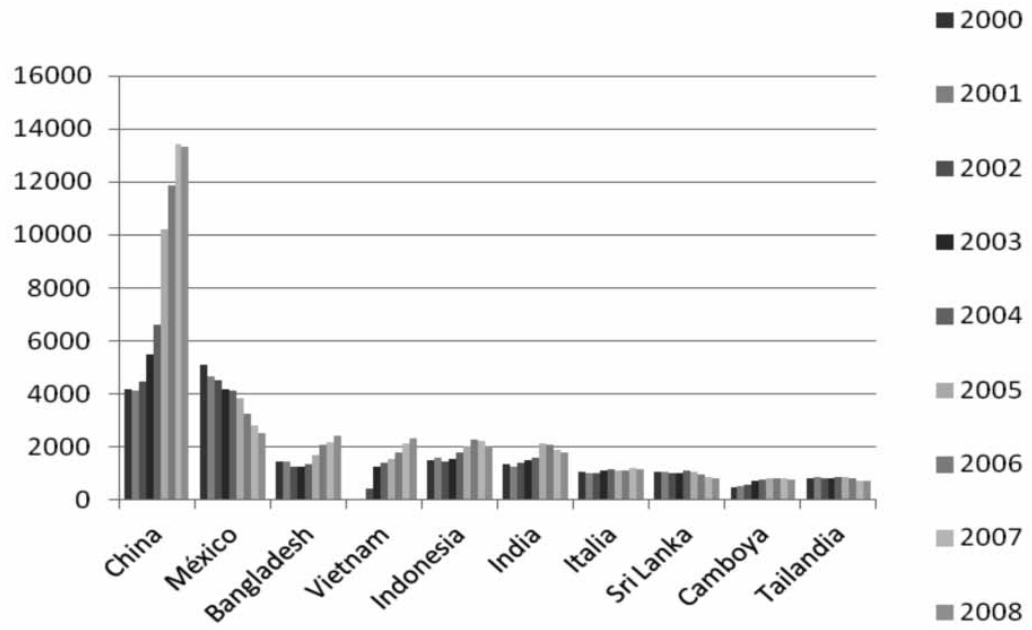

Fuente: Elaboración propia con base en Foreign Trade (2010). 


\section{Gráfica Ib \\ EU: importaciones del capítulo 63 \\ (millones de dólares)}

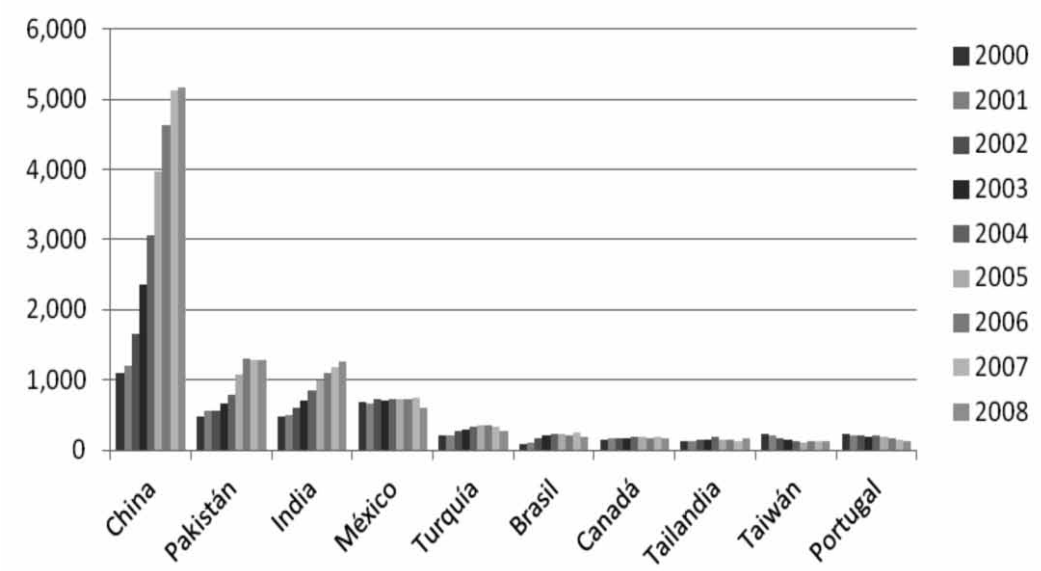

Fuente: Elaboración propia con base en Foreign Trade (2010).

\subsection{Capitulo 61. Prendas y complementos (accesorios) de vestir, de punto}

A partir del año 2000 las exportaciones mexicanas pierden importancia en la economía de EU; en dicho año representaban 13.3\%, en 2008 dicha participación había descendido a 4.3 por ciento.

China se ha consolidado como el mayor proveedor a EU en el capítulo 61. A partir del año 2003 desplazó a México como líder en ventas a ese país.

En el año 2000 China vendía en el mercado de EU 2,034 mdd, equivalente a $7.7 \%$ del total importado; en 2005 la cifra aumentó a 6,575 mdd (19.7\%); en 2008 exportó 10,684 mdd, es decir, 28.6 por ciento.

En la gráfica II se observa la evolución de las importaciones de EU provenientes de China y México. El año 2003 representó el rompimiento en la competencia México-China, año a partir del cual China le gana a México su posición como principal proveedor en el mercado de EU. De 2000 a 2008 se observó una tendencia decreciente para el caso mexicano y creciente para China. México disminuyó sus exportaciones en el periodo de referencia en más de $100 \%$; en contraste, en el mismo periodo China la incrementó $425 \%$. El resultado es que para el año 2008, en el capítulo 61, China superó en más de 9,087 mdd a las exportaciones mexicanas destinadas al mercado de EU. En este capítulo las exportaciones mexicanas representaron únicamente $14 \%$ de lo exportado por China al mercado de EU. 


\section{Gráfica II \\ EU: importaciones capítulo 61 \\ (millones de dólares)}

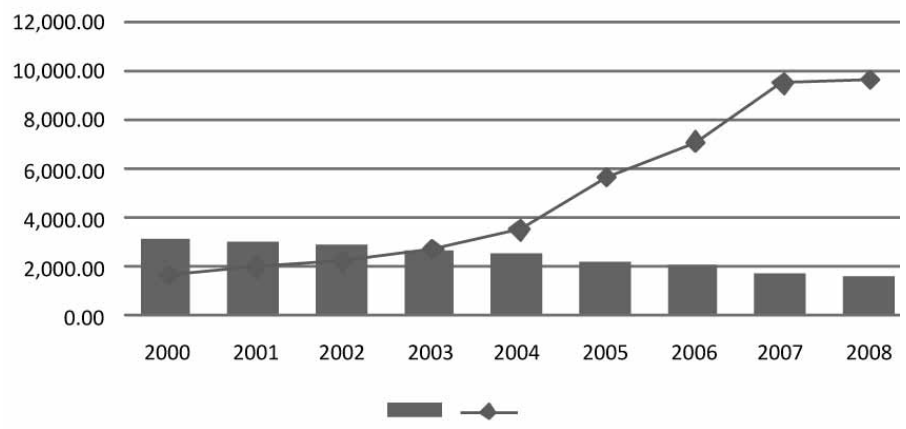

Fuente: Elaboración propia con base en Foreign Trade (2010).

En el capítulo 61 no todas las ramas se pueden comparar, en algunas de ellas el Sistema Armonizado de Designación y Codificación de Mercancías no las homologa, es el caso de las partidas 6109, 6115, 6104, 6108,6116 y 6101.

En el cuadro 5 se muestra en el capítulo 61 un crecimiento de las exportaciones de China a EU del orden de $425 \%$. Si revisamos por partida observamos que la 6115 tuvo un crecimiento de 9,887\%, la 6101 aumentó $7.42 \%$; la 6104 se incrementó $2,047 \%$; la 6111 creció $1,515 \%$; la 6108 incrementó sus exportaciones 1,329\%. Para la economía China la rama 6110 es la más importante, representó 55\% del total exportado dentro del capítulo 61.

En contraste, para el caso de México se observó lo siguiente: decremento en sus exportaciones a EU del orden de 54.5\%. La partida 6115 disminuyó 46.5\%; la 6101 tuvo un crecimiento irrisorio de 3.2\%; la 6104 descendió 63\%; la 6109 bajó 50\%; la 6108 disminuyó 75.3\%. La única partida que tuvo un crecimiento moderado fue la 6116 (115\%), que corresponde a guantes, manoplas y mitones de punto.

\subsection{Capitulo 62. Prendas y complementos (accesorios) de vestir, excepto los de punto}

De los capítulos 61 a 63,54\% de lo exportado por México correspondió al capítulo 62, durante 2008 las exportaciones fueron de 2,533 mdd; en el mismo ańo y capítulo, las exportaciones de China ascendieron a 13,316 mdd. 


\section{Gráfica III \\ EU: importaciones del capítulo 61, 2000-2008 \\ (millones de dólares)}

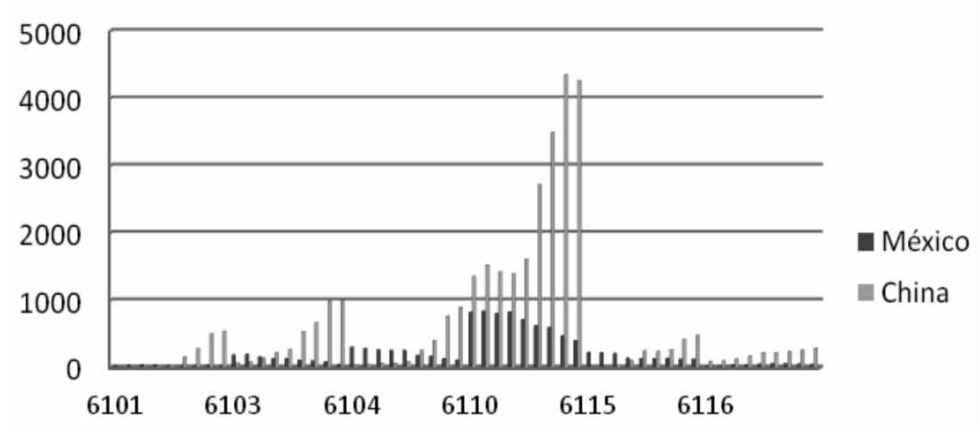

Fuente: Elaboración propia con base en Foreign Trade (2010).

\section{Gráfica IV}

EU: importaciones del capítulo 62

(millones de dólares)

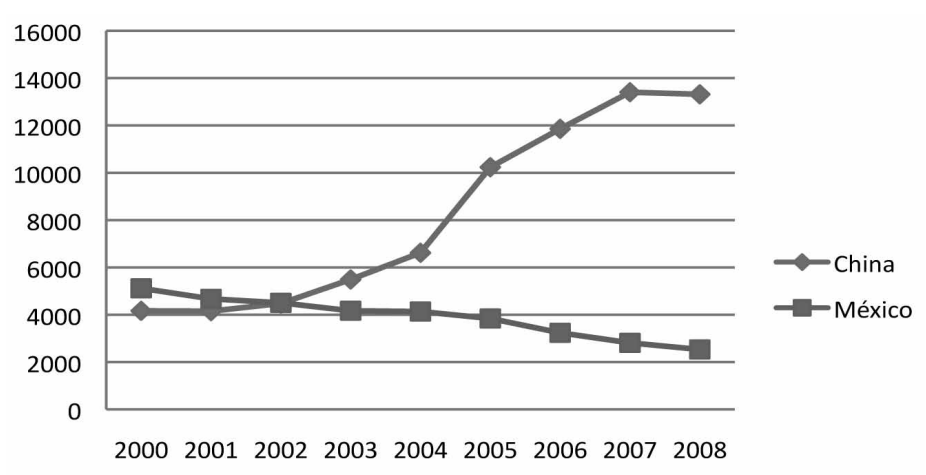

Fuente: Elaboración propia con base en Foreign Trade (2010).

En la gráfica iv se refleja la evolución de las importaciones estadounidenses de productos del capítulo 62; se detecta un abismo en las exportaciones mexicanas y chinas destinadas a Estados Unidos. El año 2002 representó el rompimiento en la ventaja de México sobre China, a partir de dicho año este último superó a México en el total exportado al mercado de EU. Las exportaciones mexicanas descendieron 50.5\%; en contraste, las exportaciones Chinas crecieron 219.5\%. El aumento de las exportaciones de China a EU fue en parte resultado de la tercera etapa en la eliminación de cupos (enero de 2002); en enero de 2005 se implementaron la cuarta y última etapas. 
En el capítulo $62^{20}$ la competencia entre México y China se genera solamente en una de las nueve principales partidas exportadas a EU. ${ }^{21} \mathrm{En}$ el año 2000 México exportó a EU 15.6\% y China 12.7\%; en 2005 México había descendido su participación a 10.2\%, China la había incrementado a 27.3\%; para 2008 México fue proveedor de EU en tan sólo 7.1\%, mientras que China participó con $37.3 \%$. Estos datos muestran una brecha que se amplía cada vez más entre las dos naciones.

En el capítulo 62 no es posible evaluar las partidas 6209 y 6217, pues el Sistema Armonizado de Designación y Codificación de Mercancías no homologa dichas ramas para los dos países.

Entre los años 2000 y 2008 las exportaciones de China a EU por partida evolucionó así: creció en total 219.5\%; la 6204 tuvo un aumento de 241.3\%; la 6206 se incrementó 142\%; la 6202, 351\%; la 6212, 503\%; la 6205 creció $244 \%$; la 6201, 133\%; la 6210, 174\%; la 6211, 240\% y la 6209 aumentó $432 \%$ (cuadro 6).

Para el caso mexicano tenemos un fenómeno contrario, en las exportaciones a EU todas las partidas, con excepción de la 6201, tuvieron decrementos. La partida 6203 pasó de 2,114.25 a 1,490 mdd, lo que representó un descenso de $206.7 \%$; el resto de las partidas perdieron mercado en EU, la 6204 un 73\%; la 6211, 3.2\% y la 6210, 53.7 por ciento.

Cabe destacar la partida 6203, en la cual México registró mayor volumen de exportación que China. En el año 2008 México exportó a EU 1,490 mdd y China $1,322.92 \mathrm{mdd}$. No obstante lo anterior, existen focos rojos en dicha partida: mientras en los últimos años se observó para México una tendencia descendente, China la tuvo creciente, que de seguir así en un plazo de dos ańos habrá superado a México (cuadro 7).

Para el resto de las partidas revisadas del capítulo 62, el principal proveedor a EU fue China, con un volumen de ventas cinco veces superior al de México.

De los tres capítulos de referencia, es en el 62 donde se generó el cambio más drástico. Si consideramos las exportaciones de México y China al mercado de EU, México era el principal proveedor; a partir del año 2003 China se apoderó de la mayor cuota de mercado, en 2005 ya triplicaba las exportaciones mexicanas, en 2008 las quintuplica. Hasta 2008 México no había perdido el segundo lugar como proveedor en el mercado de EU; no obstante, está en riesgo de ser desplazado por países como Bangladesh, Vietnam, Indonesia e India (gráfica Ib).

\footnotetext{
${ }^{20}$ Los artículos que se incluyen en el capítulo 62 se describen en la nota 6 de este trabajo.

${ }^{21}$ Las partidas en las que no hay competencia porque no coinciden las ramas del capítulo son: 6209, prendas y complementos (accesorios) de vestir, para bebés; y 6217, los demás complementos de vestir confeccionados; partes de prendas o de complementos de vestir (excepto las de la partida 6212).
} 


\section{Gráfica V \\ EU: importaciones del capítulo 62, 2000-2008 \\ (millones de dólares)}

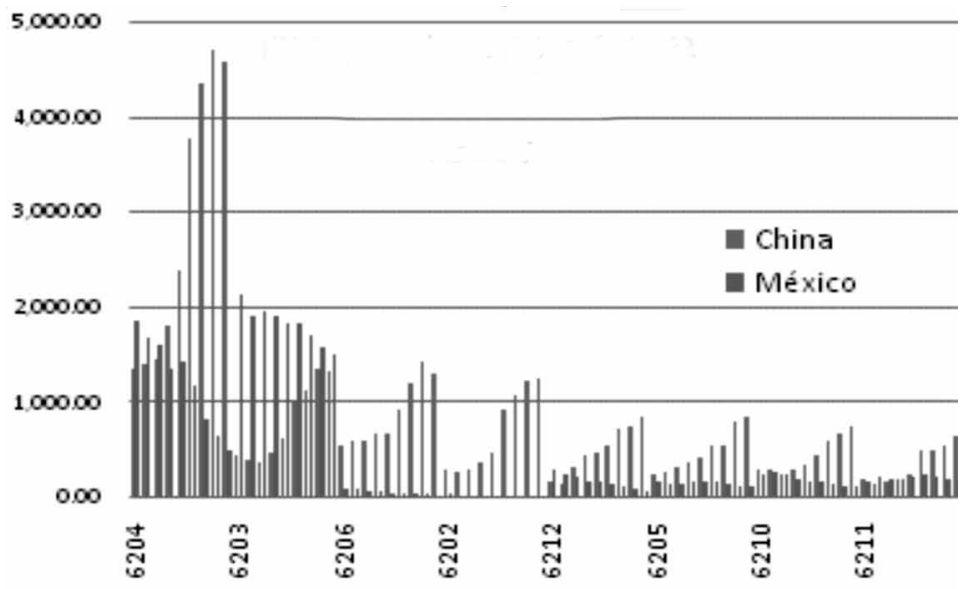

Fuente: Elaboración propia con base en Foreign Trade (2010).

\subsection{Capitulo 63. Los demás artículos textiles confeccionados, juegos, prendería y trapos}

Para el caso de México y China, en el capítulo $63^{22}$ coinciden las diez principales partidas importadas por EU, lo cual nos permite comparar todas las ramas del capítulo entre México y China; sin embargo, como se observa en los cuadro 8 y 9 , las exportaciones en volumen a EU son menores que en los capítulos 61 y 62 .

En el capítulo 63 se detecta una competencia inexistente entre México y China, en ninguna de las ramas objeto de análisis se observa la posibilidad de que México pueda en algún momento desplazar a China como el principal exportador a Estados Unidos.

A partir del ańo 2000, la marcada diferencia existente entre México y China se comenzó a profundizar. En dicho año, mientras México exportó a EU 683.5 mdd, China generó 1,101 mdd; en 2004 la brecha se había ampliado: México exportó 721.9 mdd y China 3,062; en el año 2008 las exportaciones mexicanas descendieron a $596.8 \mathrm{mdd}$, en contraste, ese año China exportó 5,168 mdd. En sólo ocho años la brecha entre México y China en el total de artículos exportados a EU del capítulo 63 se amplió de 418.3 mdd a 4,571. Cabe aclarar que si bien es cierto que

\footnotetext{
${ }^{22}$ Los artículos que se incluyen en el capítulo 63 se describen en la nota 7 de este trabajo.
} 


\section{Gráfica VI \\ EU: importaciones del capítulo 63 \\ (millones de dólares)}

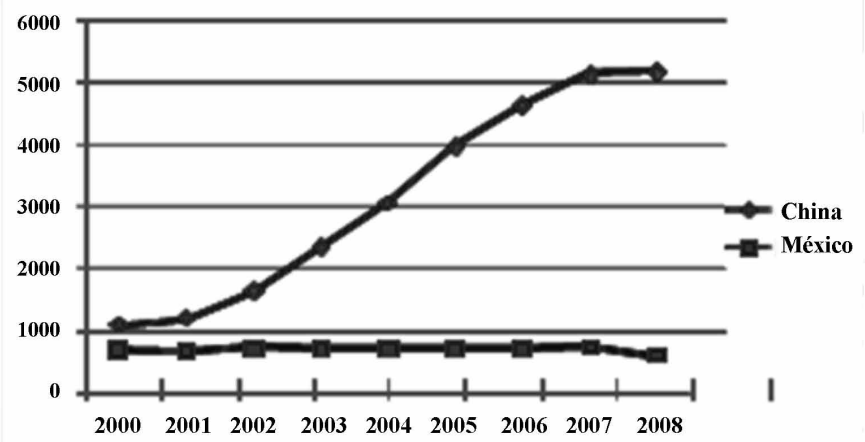

Fuente: Elaboración propia con base en Foreign Trade (2010).

la brecha creció en una gran proporción, ello no fue resultado de un fuerte descenso en las exportaciones mexicanas (12.7\%), realmente lo que impactó y amplió la brecha fue un fuerte incremento en las exportaciones de China a EU (369 por ciento).

Si se observa la evolución de las exportaciones por ramas, para el caso de México tenemos que la 6303, 6304 y 6310 crecieron 106, 47.6 y $267 \%$, respectivamente. Cabe destacar el fuerte crecimiento de las exportaciones de la partida 6310, que corresponde a trapos, cordeles, cuerdas y cordajes, de materia textil, en desperdicios o en artículos inservibles; dicha rama logró hacer frente a la apertura comercial y compite con China en el mercado de Estados Unidos. No obstante lo anterior, el problema de fondo para México es la necesidad de crear y mantener la competitividad en todos los sectores productivos del país, de lo contrario, las ramas que aún mantienen crecimiento en sus exportaciones al resto del mundo, se seguirán deteriorando.

Durante el periodo de referencia, todas las ramas de China incrementaron sus exportaciones a EU; sin embargo, es de destacar la rama 6310, que aumentó sus exportaciones en $8,175 \%$. La rama que tuvo el crecimiento más bajo durante el periodo fue la 6307, la cual elevó su exportación $173.5 \%$ (dato irrisorio si lo comparamos con el crecimiento de otras ramas del capítulo 63). 


\section{Gráfica VII}

EU: importaciones capítulo 63, 2000-2008

(millones de dólares)

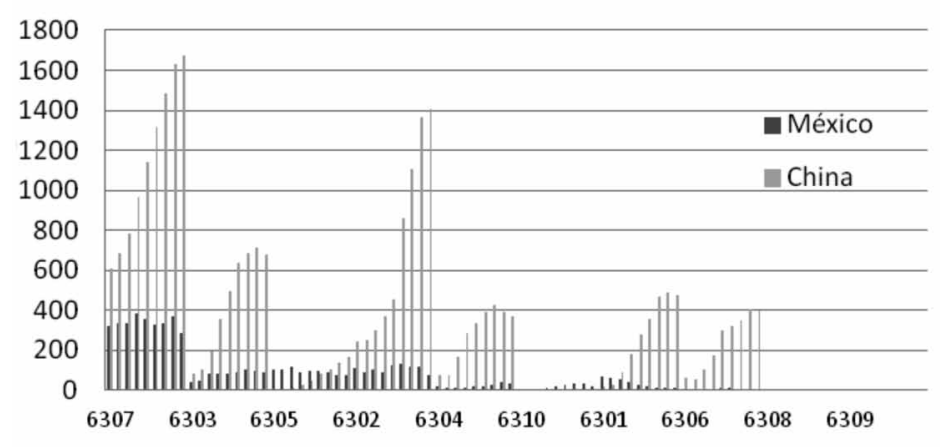

Fuente: Elaboración propia con base en Foreign Trade (2010).

\section{Fortalezas, oportunidades, debilidades y amenazas para exportar a Estados Unidos}

Para mostrar los resultados obtenidos, se decidió dividir esta sección con base en el sistema FODA, acrónimo de fortalezas, oportunidades, debilidades y amenazas.

Las fortalezas son las capacidades y habilidades que posee la empresa, las cuales le dan una posición por encima de la competencia. Las oportunidades están representadas por los factores que son favorables y con posibilidad de ser explotadas, se encuentran en el entorno de la empresa y le permiten obtener ventajas competitivas. Las debilidades son los factores que originan desventaja frente a la competencia, por ejemplo, aquello de lo que se carece (habilidades, actividades, etc.). Las amenazas se originan en el entorno y pueden llevar a la desaparición de la empresa.

Cada uno de los componentes del sistema FODA tienen diferentes características; las fortalezas y las debilidades son internas a la organización, por lo que se puede influir directamente sobre ellas. Las oportunidades y las amenazas son externas, por lo que es complicado modificarlas.

\subsection{Fortalezas y oportunidades para México}

a) Vecino del principal importador mundial, que además representa el mercado de consumo más grande del mundo. 
b) La ventaja geográfica señalada le permite a México tener costos de transporte inferiores al de sus principales competidores (con excepción de Canadá). ${ }^{23}$ México exporta la mayor parte de sus productos vía terrestre, lo que le permite tener un bajo costo de transporte, que asciende a $1.1 \%$ del valor de sus exportaciones totales. China paga un costo de transporte más alto con respecto al valor total de sus exportaciones: $6.3 \%$, es decir, casi seis veces superior al de México. ${ }^{24}$

c) En el cuadro 10 se observa que el índice ${ }^{25}$ de manipulación de carga se mantiene igual en los dos países; sin embargo, los índices de eficiencia portuaria, de criminalidad y el de desendeudamiento interno es menor en México.

d) La reducción internacional en los costos de transporte marítimo ha disminuido la ventaja comparativa que tenía México en relación con otros países que comercian con EU; sin embargo, es importante matizar que a distancias más largas existe mayor posibilidad de que se presenten problemas vinculados con el traslado de las mercancías, lo que es un elemento decisivo que favorece a México y que difícilmente podrá cambiar en el futuro cercano. Por ende, coincidimos con Harrigan y Venables (2004: 2) quienes sostienen que los costos de transporte son cuantitativa y cualitativamente importantes, argumentan la importancia de sincronizar las tareas que incentivan el proceso de aglomeración porque la producción requiere la concentración de todas las fábricas de componentes junto a las plantas de ensamblaje.

e) En México el tiempo medido en días para exportar un producto desde que se realiza el contrato hasta que llega a su destino final es de 14 días, en China es de 21. ${ }^{26}$

${ }^{23}$ Lo anterior no significa que dichas ventajas se mantengan a lo largo del tiempo, hay indicios de que los costos de transporte están dejando de tener importancia en el comercio internacional. Para profundizar en el tema véanse Herrera (2005) y Krugman (1991).

24 "El tema es muy relevante desde múltiples perspectivas, incluyendo la comparación con los aranceles efectivamente pagados en 2006: la tasa arancelaria por el total de las importaciones estadounidenses fue de $1.36 \%$, mientras que fue de $3.01 \%$ y de $0.11 \%$ para China y México, respectivamente. Es decir, el costo del transporte de las exportaciones de China y México fue un 208\% y $1,036 \%$ más alto que el de sus aranceles. En términos de política comercial en Estados Unidos e incluso a nivel global, sin embargo, la mayor parte del debate sobre política comercial se ha concentrado en los aranceles" (Dussel, 2008: 17).

${ }^{25}$ El índice toma el valor de 0 si no existe restricción, 0.25 para las restricciones de menor importancia, 0.5 si se impone una condición conjunta, 0.75 si es una participación nacional muy alta y 1 si se prohíbe a las empresas extranjeras manipular la carga de servicios

${ }^{26}$ No obstante la diferencia de siete días, debemos considerar la mayor distancia que tienen los productos chinos para llegar al mercado de EU. "El tiempo se registra en días calendario. El cálculo de tiempo para un procedimiento comienza desde el momento en que se inicia éste hasta el momento en que se completa. Si se puede acelerar un procedimiento a un costo adicional, se elige el procedimiento legal más rápido. Se supone que ni el importador ni el exportador pierden tiempo y que 


\subsection{Debilidades y amenazas para México}

a) Prácticas desleales de China -como el dumping, la triangulación y el contrabando- son elementos que afectan seriamente la ITC mexicana (Labiano y Loray, 2006: 13; Rodríguez y Fernández 2007: 9).

b) En el cuadro 10 se observa que el índice de manipulación de carga se mantiene igual en los dos países; sin embargo, los índices de servicios obligatorios y de acuerdos de cooperación es mayor en México.

c) Hummels (2001: 26-27) señala que a mayor distancia el comercio se reduce, sin embargo matiza que para productos grandes existe una voluntad mayor a pagar más por el ahorro de tiempo, no así para los productos pequeños. Un elemento importante que tiene efectos fuertes en los costos de transporte es la relación peso-valortamaño de los productos. Las mercancías de la ITC tienen la particularidad de tener un peso-tamaño promedio bajo, por lo que México tiene desventaja en dicho rubro.

d) La Corporación Financiera Internacional, perteneciente al grupo del Banco Mundial (BM, 2010: 51), detecta que México no es competitivo para transportar sus mercancías. En promedio el costo por contenedor es de 1,472 dólares, en China el costo es de 500; Dussel (2008: 40) argumenta que la principal limitación en el transporte del comercio exterior mexicano es la incertidumbre en términos de tiempo: diversos permisos, incertidumbre en las aduanas en torno a la revisión exhaustiva de la mercancía, así como otros procesos de verificación de documentos y de mercancía (cuadro 11).

e) Algunos estudios muestran que México no sólo presenta altos costos arancelarios y no arancelarios (comparado inclusive con economías como Brasil, Colombia, Argentina, Japón y Canadá), sino que además los costos de las barreras no arancelarias (telecomunicaciones, energía y transporte) son superiores a las arancelarias (OCDE, 2007: 9-10).

f) En materia de comercio exterior, la OCDE encuentra que México -como miembro de dicho organismo- muestra estadísticas abismales en relación con los otros países miembros. Todas las variables consideradas en comercio transfronterizo (costos, tiempo, número 
de documentos para exportar e importar ${ }^{27}$ son más elevadas en México que en el resto de países miembros (cuadro 12).

g) Las debilidades de la ITC son resultado de dos factores principales: la baja productividad de la industria mexicana y que el principal mercado de exportación de México fue invadido por productos chinos de bajo costo. En una investigación reciente, Hanson y Robertson señalan que "China es responsable sólo de una pequeña fracción de la disminución de las ventas mexicanas hacia los Estados Unidos, el grueso de la responsabilidad recae en factores internos que limitan la propia capacidad de exportación del país (en López et al., 2009: 131).

\subsection{Fortalezas y oportunidades de China}

a) La entrada de China a la omc fue uno de los factores que favoreció su influencia comercial, particularmente en el mercado estadounidense. La inserción de China se favoreció por la supresión de cuotas y aranceles en la ITC; ello aunado a que la ITC de China se centró en la producción de artículos más baratos y mayor volumen.

b) Desde la década de los ochenta, China cuenta con la experiencia en procesos de paquete completo y en la generación de un importante sistema de proveeduría de producción textil. Este país además ha integrado una buena parte de los segmentos de la cadena de valor. En la actualidad cuenta con las empresas nacionales y globales de proveeduría e insumos para realizar prácticamente la totalidad de productos, esto es, se genera paquete completo (Quinliang, 2004: 172-174; Cárdenas y Dussel, 2007: 531).

c) Si comparamos a China con México, observamos que la proporción de los costos es de tres a uno a favor de China, pero en el caso de la productividad es de dos a uno para México. Aunque hay un diferencial de costos significativo entre China y México, el diferencial de productividad elimina parte de esa ventaja (Duana et al, 2009: 10).

d) Las instituciones, la infraestructura, la estabilidad macroeconómica, la salud, la educación primaria, la eficiencia en los mercados y la formación para el trabajo son mejores en China que en México. De acuerdo con el IGC, en lo único que México es mejor que China es en la disposición tecnológica y en el tamaño del mercado.

e) Es fundamental comprender la profunda integración productiva y comercial entre Hong Kong y China: las empresas de Hong Kong

${ }^{27}$ Este tema incluye los procedimientos requeridos para importar y/o exportar carga estandarizada de bienes. Se tiene en cuenta cada paso en el procedimiento -desde que se elabora el contrato hasta la entrega final de los bienes-, considerando el tiempo necesario para completar el proceso. 
durante los noventa, e incluso antes de su incorporación a China (1 de julio de 1997), ya habían transferido una parte de los segmentos de menor valor agregado a China, y en particular a las empresas propiedad del Estado. Esta experiencia le ha permitido a China incrementar sustancialmente el nivel tecnológico en las plantas, así como mejorar los canales de ventas y distribución internamente y en el exterior (Dussel y Liu, 2004: 65).

f) China cuenta con la mayor conectividad ${ }^{28}$ de transporte marítimo en líneas regulares: "Un número elevado de buques es claramente un indicador de las mayores oportunidades que tienen a su disposición los exportadores de un país para cargar sus exportaciones contenedorizadas, encontrándose por ejemplo mejor conectados con mercados exteriores. El país con el mayor número de buques desplegados es China con 1,228 naves, seguido por Hong Kong (China) con 1,166 y EU con 1,074" (Martínez y Hoffmann, 2007: 46).

g) La tela como insumo participa con alrededor de $50 \%$ de los costos totales del producto. La diferencia de costos entre una tela fabricada en China y otra en EU era de aproximadamente 50\% antes del fin de las restricciones para China. Incluye costos de fletes, cuotas y aranceles. Posterior a 2005, las telas producidas en dicho país son aún más competitivas en costos que las producidas en México, utilizan insumos estadounidenses para beneficiarse de las preferencias arancelarias (Dussel y Liu, 2004: 61).

h) De acuerdo con el IGC, durante 2008 y 2009 China se ubicó en el lugar 30, en 2009-2010 se posicionó en el lugar 29, ${ }^{29}$ esto es, mejoró su posición en el ranking mundial.

\subsection{Debilidades y amenazas para China}

a) Dado que su uso es intensivo, el bajo costo de la mano de obra es la principal ventaja en la industria de la confección. No obstante lo anterior, existen indicios que muestran que dicha ventaja se está perdiendo en China. Con datos de 2009 (cuadro 13) se observa que el crecimiento de los salarios en la industria manufacturera por hora durante el periodo 2000-2008 creció $0.2 \%$ en Japón, en España $40 \%$, en EU 32.4\%, en China 177.2\%, para el caso de México se observa un aumento en este periodo de $61.2 \%$ (oIt, 2009).

\footnotetext{
${ }^{28}$ Los autores definen la conectividad como los accesos a los servicios de transporte.

${ }^{29}$ Si consideramos Taiwán-China, pasó del lugar 17 al 12.
} 
b) China se enfrenta con la competencia de países como India, Pakistán y República Dominicana, naciones que cuentan con fuerza de trabajo más barata que China. El salario en India asciende a 95 dólares al mes, en Pakistán 53, en República Dominicana 166 y en China 196.8 dólares (ort, 2009).

c) Aunque se percibe la ventaja de China en el sector transporte, cabe destacar que el costo del mismo se vincula fuertemente al precio de los hidrocarburos, por ende, el costo es variable; en este sentido es posible que el precio de los hidrocarburos se mantenga a la alza, y de alcanzarse un precio cercano a los 200 dólares por barril de petróleo, el costo de transporte subirá al doble y en consecuencia no será rentable transportar productos en contenedores. Por tanto, las ventajas salariales de China, que además se han visto disminuidas en los últimos años, se cancelarán frente al incremento en el costo de transporte. Con información del Canadian Imperial Bank of Commerce (Сівс), en el año 2000, con un precio del barril de petróleo a 20 dólares, el costo de transporte equivalía a un arancel de 3\%; actualmente, dado el precio de 80 dólares por barril, ese costo se incrementa a $9 \%$. Si llega a 200 dólares el barril, los costos de transporte serán equivalentes a la tasa arancelaria que existía a mediados de los años sesenta (El Siglo, 2008).

d) La confección en China requiere importar la mayor parte de sus insumos textiles (oMC, 2009). En el año 2000 importó 12,832 mdd, en 2008 necesitó importar 16,228 mdd, esto es, China tuvo un crecimiento porcentual en sus importaciones de textiles de $26.5 \%$. Por ende, una amenaza latente es la dependencia que tiene la industria de la confección de la industria textil extranjera.

\section{Conclusiones}

Si México no quiere que una de las industrias del sector manufacturero que más empleos genera pierda mayor relevancia en la economía, deberá desarrollar nuevas estrategias de competitividad mediante la aplicación de tecnología y conocimiento en sus procesos productivos, así como mejorar la capacitación de sus trabajadores, lo cual redundará en productos relativamente más baratos que los de la competencia y en la generación de mayor calidad en los productos elaborados dentro de la cadena.

Hoy las empresas que compiten en el mercado mundial, y en particular dentro de EU, ya no son empresas aisladas que operan en forma descentralizada, sino clusters industriales, grupos de empresas constituidos en redes, cuya dinámica depende de la eficacia de su ubicaciones industriales, es decir, de la existencia de universidades, centros de entrenamien- 
to, centros de I+D, sistemas de información tecnológica y organizaciones sectoriales privadas.

La poca o nula experiencia mexicana en venta de paquete completo significa una importante área de oportunidad que México deberá explotar. Las exigencias de los clientes son cada vez mayores, sin duda preferirán al proveedor que mejor atienda sus necesidades al menor costo.

México se mantiene entre los cinco principales países proveedores en el mercado de EU; sin embargo no es posible comparar los niveles de exportación de todas las ramas de México y de China, simplemente porque no existe una competencia reñida en volúmenes de venta hacia el mercado de EU, por ejemplo la rama mexicana 6116 es una de las pocas que mejor afrontó la competencia china y vio crecer su mercado en EU: durante el año 2008 exportó 45.7 mdd; en el mismo periodo y rama, China exportó a EU 285.4 mdd, esto es, 239.6 más que México.

En el año 2000 la posición de México era la de un líder evidente, actualmente ya no lo es en el total de ramas que componen los capítulos 61 a 63. En 2000, en las ramas pertenecientes a los capítulos 61 y 62, México exportó más que China; sin embargo, ése fue un año de bonanza, a partir de entonces China superó a México en casi todas las ramas analizadas. En el capítulo 63, antes del año 2000, China ya era superior a México en volumen exportado.

Es posible destacar algunas ramas en las cuales México logró afrontar la competencia de China: del capítulo 61 podemos señalar la partida 6116 correspondiente a guantes, manoplas y mitones de punto, sus exportaciones destinadas al mercado de EU crecieron 115 por ciento.

Del capítulo 62 destaca la rama 6203, en la cual durante 2008 México registró mayores exportaciones que su principal competidor asiático. México exportó a EU 1,490 mdd, China exportó 1,322.92. No obstante, existen focos rojos en dicha partida, pues mientras en los últimos ańos se observa para México una tendencia descendente, China tiene una tendencia creciente, que de seguir así, en un plazo de dos años habrá superado a México.

Cabe destacar las ramas mexicanas 6303, 6304 y 6310, cuyas exportaciones durante el periodo 2000-2008 crecieron 106, 47.6 y 267\%, respectivamente; asimismo se enfatiza el fuerte crecimiento de las exportaciones pertenecientes a la partida 6310, que corresponde a trapos, cordeles, cuerdas y cordajes, de materia textil, en desperdicios o en artículos inservibles, la cual logró hacer frente a la apertura comercial y disputa con China del mercado de EU.

También es importante señalar que cinco de las 30 ramas analizadas lograron incrementar sus exportaciones al mercado de EU, por ello, es una verdad a medias que la ITC se encuentra en total retirada y no pueda 
competir con China en el mercado de EU. Si consideramos los productos, México deberá trabajar arduamente en la producción con calidad de guantes, mitones y manoplas, de punto; trajes (ambos o ternos), conjuntos, chaquetas (sacos), pantalones largos, pantalones con peto, pantalones cortos (calzones) y shorts (excepto de baño), para hombres o niños; visillos y cortinas; guardamalletas y rodapiés de cama; trapos, cordeles, cuerdas y cordajes, de materia textil, en desperdicios o en artículos inservibles; artículos de tapicería.

Se ha señalado en diferentes investigaciones la ventaja competitiva que tiene China dado el bajo costo de su mano de obra, la cual está perdiendo y puede ser una ventaja para México. En China los salarios manufactureros se incrementaron $177.2 \%$ entre 2000 y 2008; para el caso de México se observa un crecimiento de los salarios menor, 61.2 por ciento.

México deberá explotar los avances en la protección intelectual, la transparencia en reglas y los costos de las telecomunicaciones a través de la difusión. De acuerdo con el informe mundial de competitividad, México requiere mejoras urgentes que le permitan ser una economía más atractiva para hacer negocios. Entre las principales problemáticas destacan: gobierno burocrático, ineficiente y corrupto; delincuencia; falta de acceso al financiamiento; regulaciones laborales restrictivas, infraestructura inadecuada, ente otras.

Consideramos que la reactivación del sector textil y de la confección en México debe tener cuatro grandes características: 1) activa, donde el gobierno asuma su función promotora de la actividad empresarial; 2) integral, donde la competitividad del aparato productivo dependa de diversas medidas de política económica (tecnología, capacitación, comercio exterior, etc.); 3) de largo plazo, es decir, que su permanencia se garantice mediante la participación activa de los empresarios en el diseńo y aplicación de instrumentos de política industrial, y 4) debe ser consensada, esto es, que los sectores productivos participen en su elaboración. 


\section{Anexo}

\section{Cuadro 1}

\section{Los 12 pilares de la competitividad México-China. Requerimientos básicos}

\begin{tabular}{llll}
\hline \multicolumn{1}{c}{ México: } & \multicolumn{2}{c}{ China: } \\
\hline $1^{\circ}$ Pilar: instituciones & -98 & $1^{\circ}$ Pilar: instituciones & -48 \\
\hline $2^{\circ}$ Pilar: infraestructura & -69 & $2^{\circ}$ Pilar: infraestructura & -46 \\
$\begin{array}{l}3^{\circ} \text { Pilar: estabilidad } \\
\text { macroeconómica }\end{array}$ & -28 & $\begin{array}{l}3^{\circ} \text { Pilar: estabilidad } \\
\text { macroeconómica }\end{array}$ & -8 \\
$\begin{array}{l}4^{\circ} \text { Pilar: salud y educación } \\
\text { primaria }\end{array}$ & & $\begin{array}{l}4^{\circ} \text { Pilar: salud y educación } \\
\text { primaria }\end{array}$ & -45 \\
\hline
\end{tabular}

Fuente: Elaboración propia con base en World Economic Forum (2010).

\section{Cuadro 1b}

\section{Potenciadores de la eficiencia}

\begin{tabular}{|c|c|c|c|}
\hline México: & & China: & \\
\hline $\begin{array}{l}5^{\circ} \text { Pilar: educación superior } \\
\text { y formación }\end{array}$ & -74 & $\begin{array}{l}5^{\circ} \text { Pilar: educación superior } \\
\text { y formación }\end{array}$ & -61 \\
\hline $\begin{array}{l}6^{\circ} \text { Pilar: eficiencia en el } \\
\text { mercado de mercancías }\end{array}$ & -90 & $\begin{array}{l}6^{\circ} \text { Pilar: eficiencia en el } \\
\text { mercado de mercancías }\end{array}$ & -42 \\
\hline $\begin{array}{l}7^{\circ} \text { Pilar: eficiencia en el } \\
\text { mercado laboral }\end{array}$ & -115 & $\begin{array}{l}7^{\circ} \text { Pilar: eficiencia en el } \\
\text { mercado laboral }\end{array}$ & -32 \\
\hline $\begin{array}{l}8^{\circ} \text { Pilar: sofisticación del } \\
\text { mercado financiero }\end{array}$ & -73 & $\begin{array}{l}8^{\circ} \text { Pilar: sofisticación del } \\
\text { mercado financiero }\end{array}$ & -81 \\
\hline $\begin{array}{l}9^{\circ} \text { Pilar: preparación } \\
\text { tecnológica }\end{array}$ & -71 & $\begin{array}{l}9^{\circ} \text { Pilar: preparación } \\
\text { tecnológica }\end{array}$ & -79 \\
\hline $10^{\circ}$ Pilar tamaño del mercado & (11) & $10^{\circ}$ Pilar: tamańo del mercado & -2 \\
\hline
\end{tabular}

Fuente: Elaboración propia con base en World Economic Fórum (2010). 


\section{Cuadro 1c \\ Innovación y sofisticación de los factores}

\begin{tabular}{lllr}
\hline \multicolumn{1}{c}{ En México } & \multicolumn{2}{c}{ En China } \\
\hline 11. Sofisticación de & -62 & $\begin{array}{l}\text { 11. Sofisticación } \\
\text { de los negocios }\end{array}$ & -38 \\
los negocios & -78 & 12. Innovación & $(26)$ \\
12. Innovación &
\end{tabular}

Nota: los números entre paréntesis son la posición en que se ubica el país en el ranking mundial que abarca 133 países.

Fuente: Elaboración propia con base en World Economic Forum (2010).

\section{Cuadro 2}

Factores más problemáticos para hacer negocios en México y China ${ }^{a}$

\begin{tabular}{|c|c|c|c|}
\hline \multicolumn{2}{|l|}{ México } & \multicolumn{2}{|l|}{ China } \\
\hline $\begin{array}{l}\text { Ineficiente burocracia } \\
\text { gubernamental }\end{array}$ & 15.5 & Ineficiente burocracia & 11.1 \\
\hline Acceso al financiamiento & 12.3 & Acceso al financiamiento & 16.8 \\
\hline Corrupción & 12.8 & Corrupción & 7.4 \\
\hline Crimen y robo & 12.4 & Crimen y robo & 0.7 \\
\hline $\begin{array}{l}\text { Restrictivas regulaciones } \\
\text { laborales }\end{array}$ & 10.5 & Regulación laboral restrictiva & 5.4 \\
\hline $\begin{array}{l}\text { Inadecuado soporte } \\
\text { infraestructural }\end{array}$ & 8.2 & $\begin{array}{l}\text { Inadecuado soporte } \\
\text { infraestructural }\end{array}$ & 8.5 \\
\hline Tasa de impuesto & 6.1 & Tasa de impuestos & 7.1 \\
\hline educación de la mano de obra & 5.1 & Educación de la mano de obra & 7.3 \\
\hline Inflación & 3.1 & Inflación & 5.8 \\
\hline $\begin{array}{l}\text { Mala ética de trabajo } \\
\text { de la fuerza laboral }\end{array}$ & 3.1 & $\begin{array}{l}\text { Mala ética de trabajo } \\
\text { de la fuerza laboral }\end{array}$ & 5.2 \\
\hline Inestabilidad política & 2.1 & Inestabilidad política & 9.3 \\
\hline Inestabilidad gubernamental & 0.9 & Inestabilidad gubernamental & 1.3 \\
\hline $\begin{array}{l}\text { Regulación de moneda } \\
\text { extranjera }\end{array}$ & 0.9 & $\begin{array}{l}\text { Regulación de moneda } \\
\text { extranjera }\end{array}$ & 3.6 \\
\hline Salud pública & 0.5 & Salud pública & 0.9 \\
\hline Normativa tributaria & 6.4 & Regulación impositiva & 9.6 \\
\hline
\end{tabular}

${ }^{a}$ De una lista de 15 factores, a los encuestados se les pidió seleccionar los cinco factores más problemáticos para hacer negocios en su país/economía y que los clasificaran. Los datos indican las respuestas ponderadas de acuerdo con sus clasificaciones.

Fuente: Elaboración propia con base en World Economic Forum (2010). 


\section{Cuadro 3 \\ Datos comparativos México-China}

\begin{tabular}{ll}
\hline \multicolumn{1}{c}{ México } & \multicolumn{1}{c}{ China } \\
\hline $\begin{array}{l}\text { Población: 107.8 millones } \\
\text { de habitantes (lugar 11) }\end{array}$ & $\begin{array}{l}\text { Población: 1,336.3 millones } \\
\text { de habitantes (lugar 1) }\end{array}$ \\
PIB: 1,088.1 billones de dólares (lugar 13) & PIB: 4,401.6 billones de dólares (lugar 3) \\
PIB per cápita: 10,234.8 dólares (lugar 54) & PIB per cápita: 3,315.3 dólares (lugar 88) \\
$\begin{array}{l}\text { Participación porcentual en el PIB } \\
\text { mundial: 2.24\% (lugar 11) }\end{array}$ & $\begin{array}{l}\text { Participación porcentual en el PIB } \\
\text { mundial: } 11.40 \% \text { (lugar 2) }\end{array}$ \\
\hline
\end{tabular}

Fuente: Elaboración propia con base en World Economic Forum (2010). 


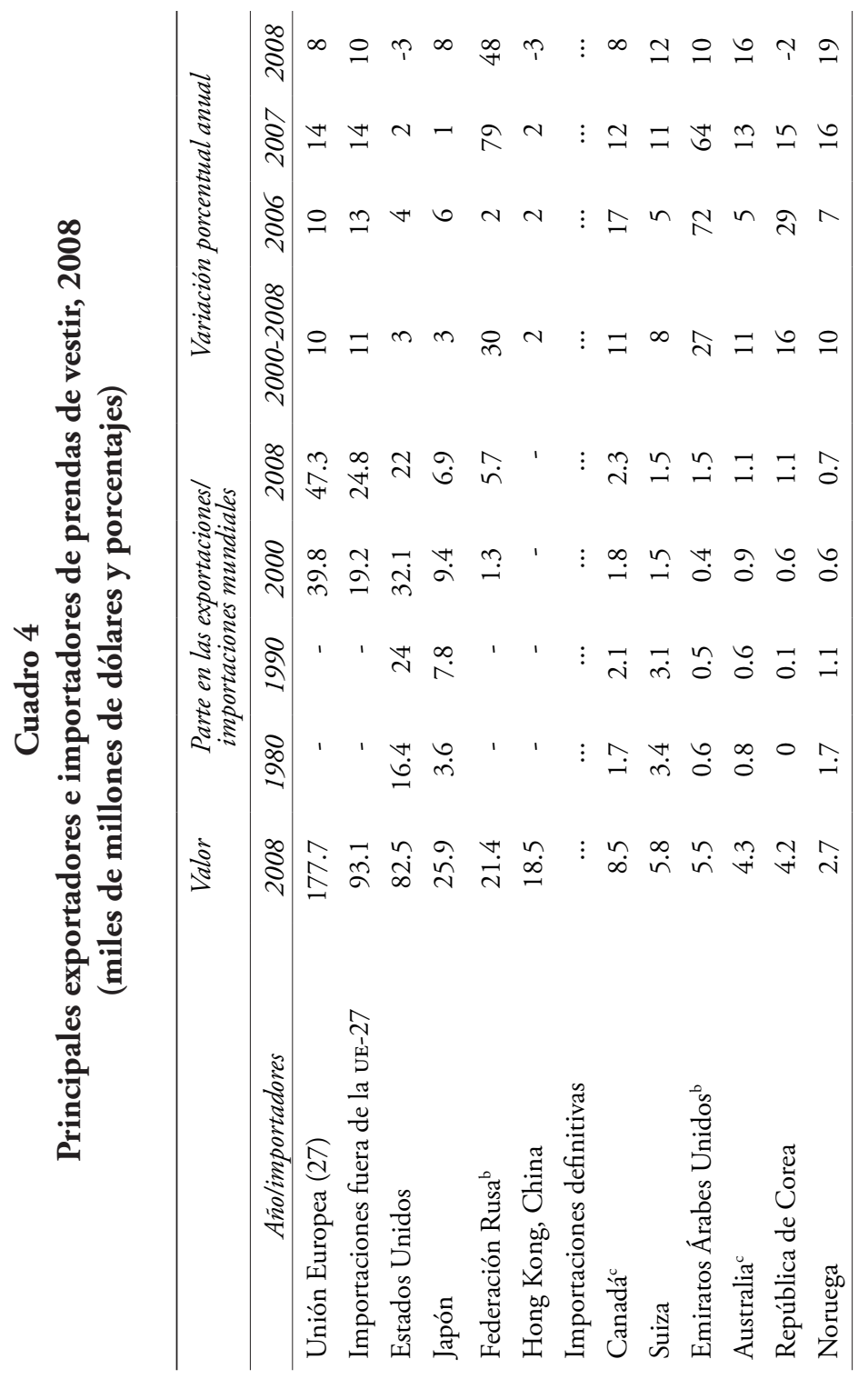




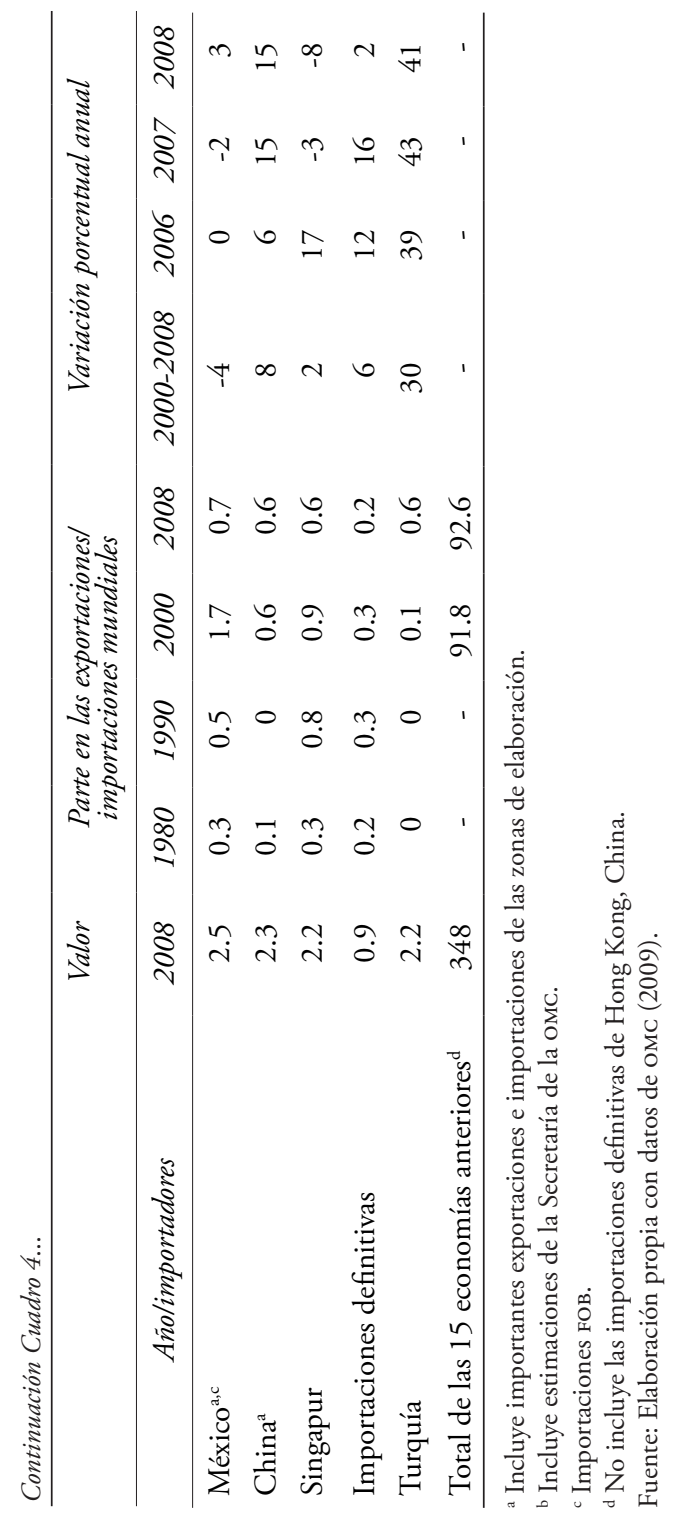




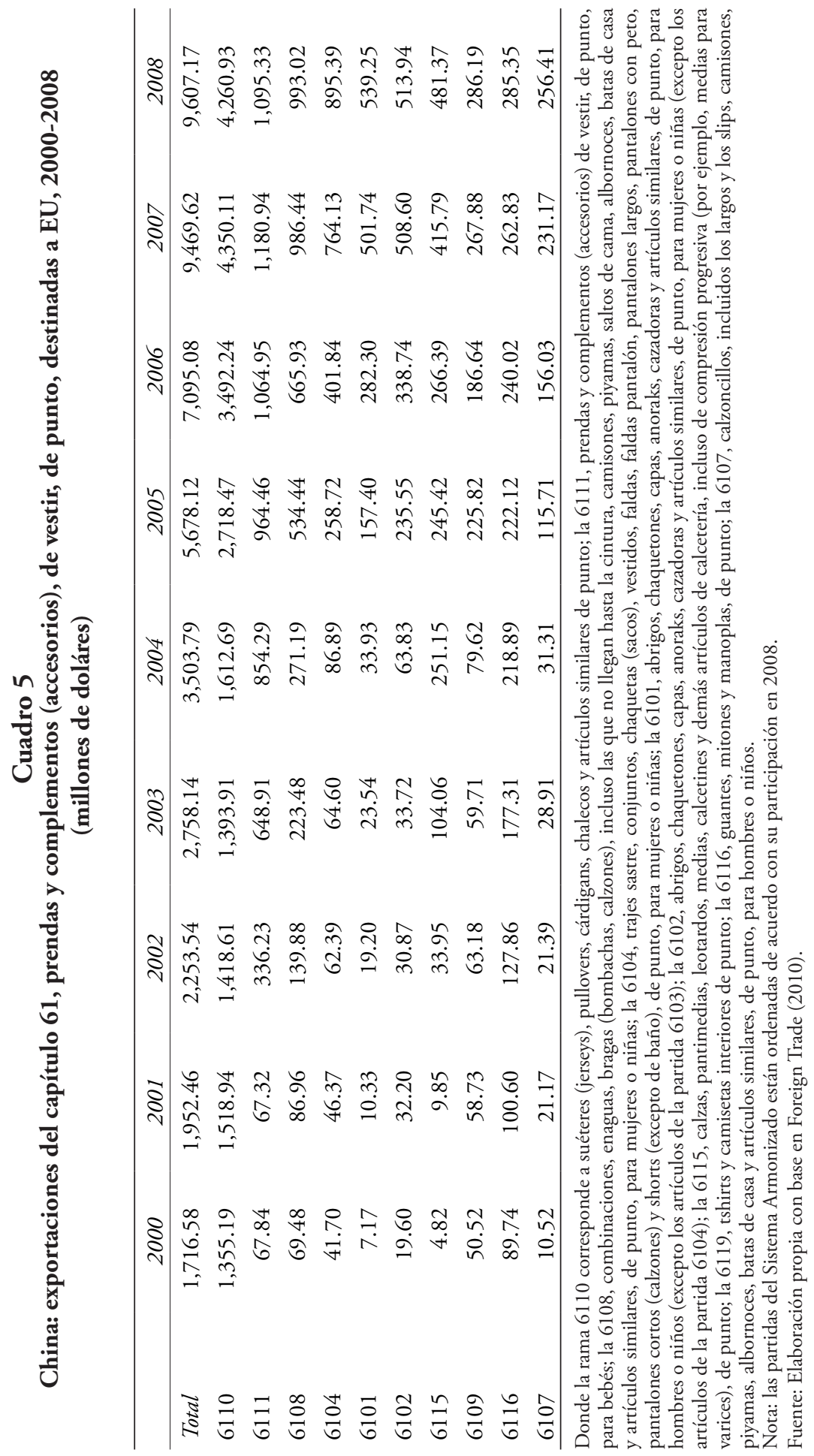




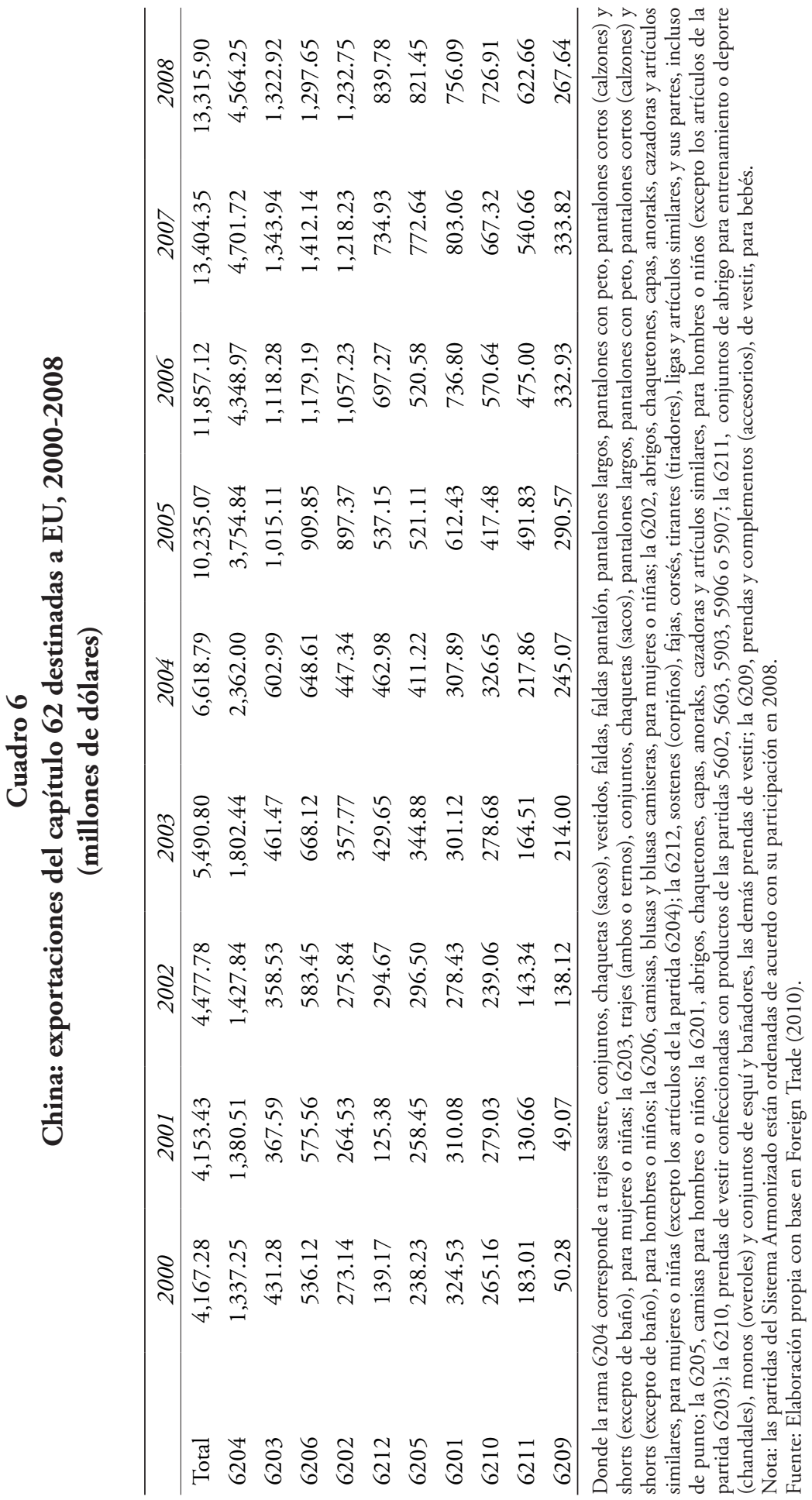




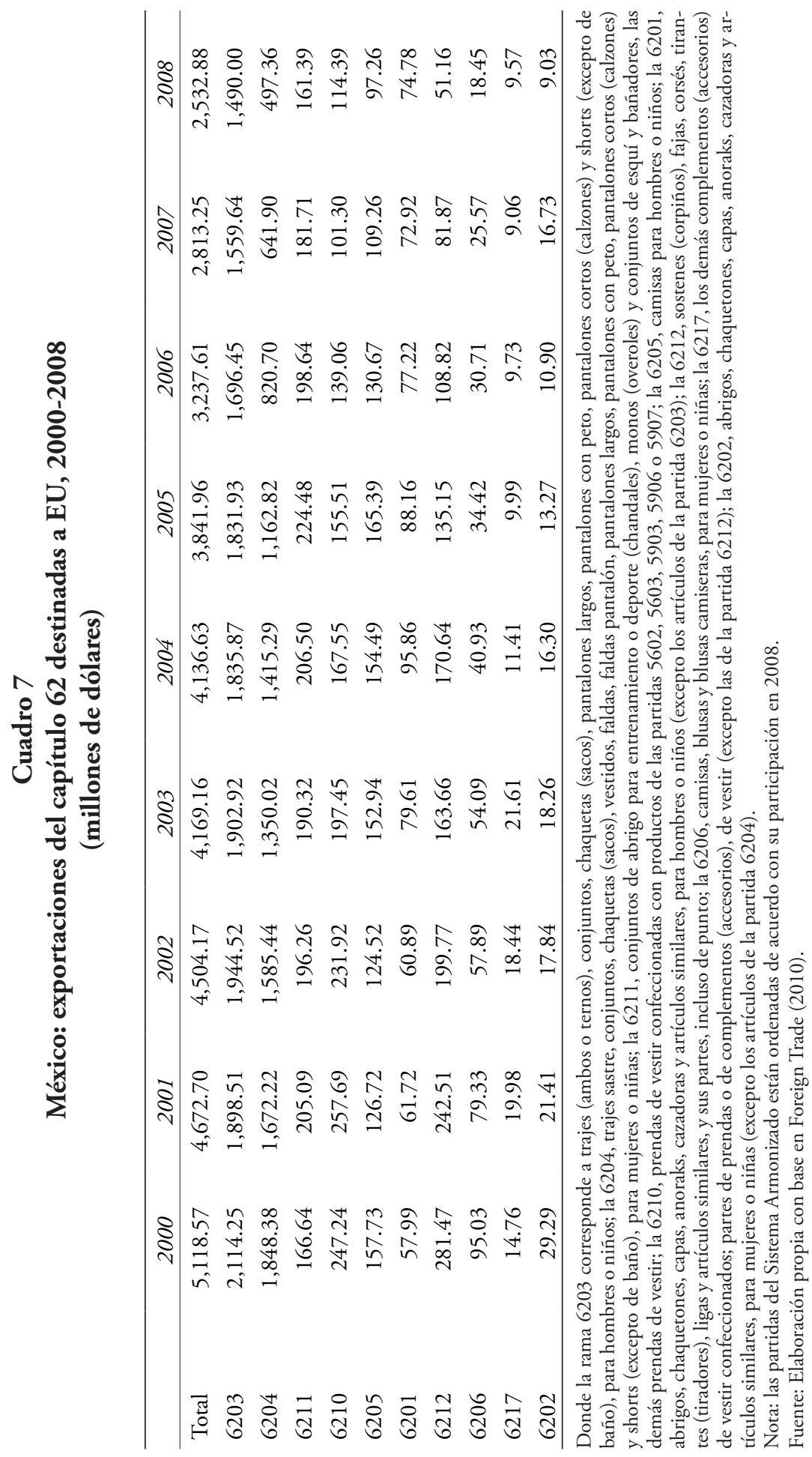




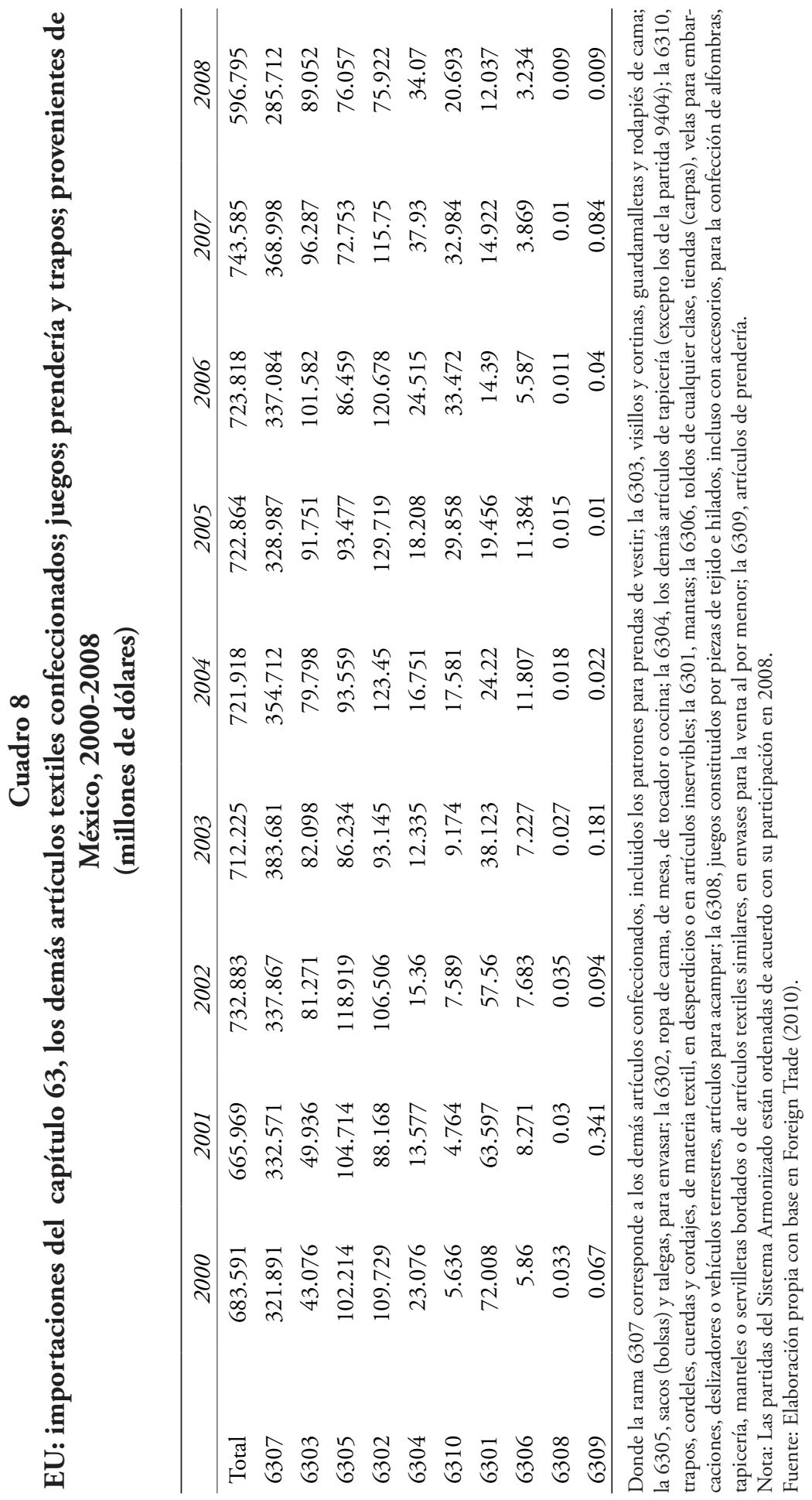




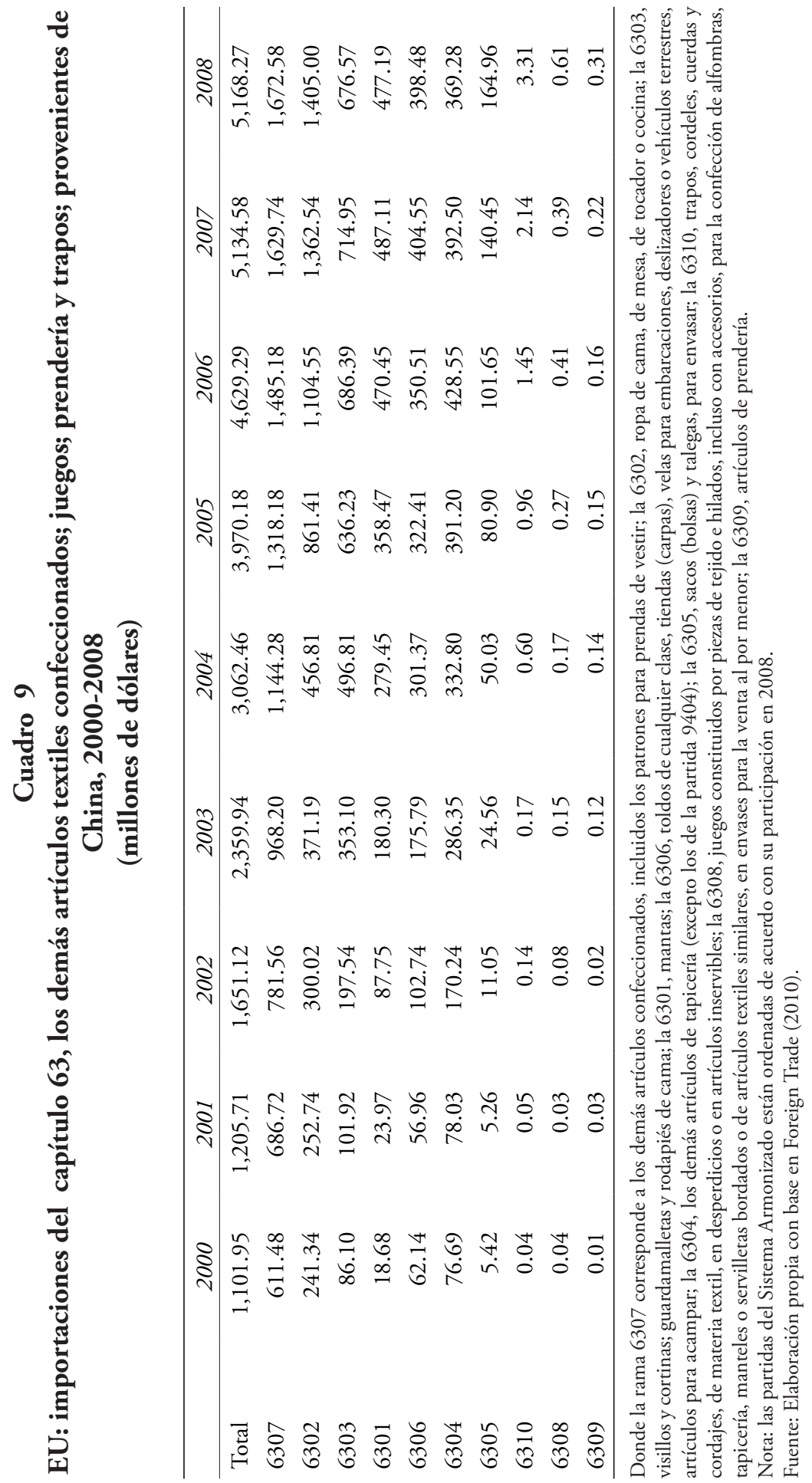




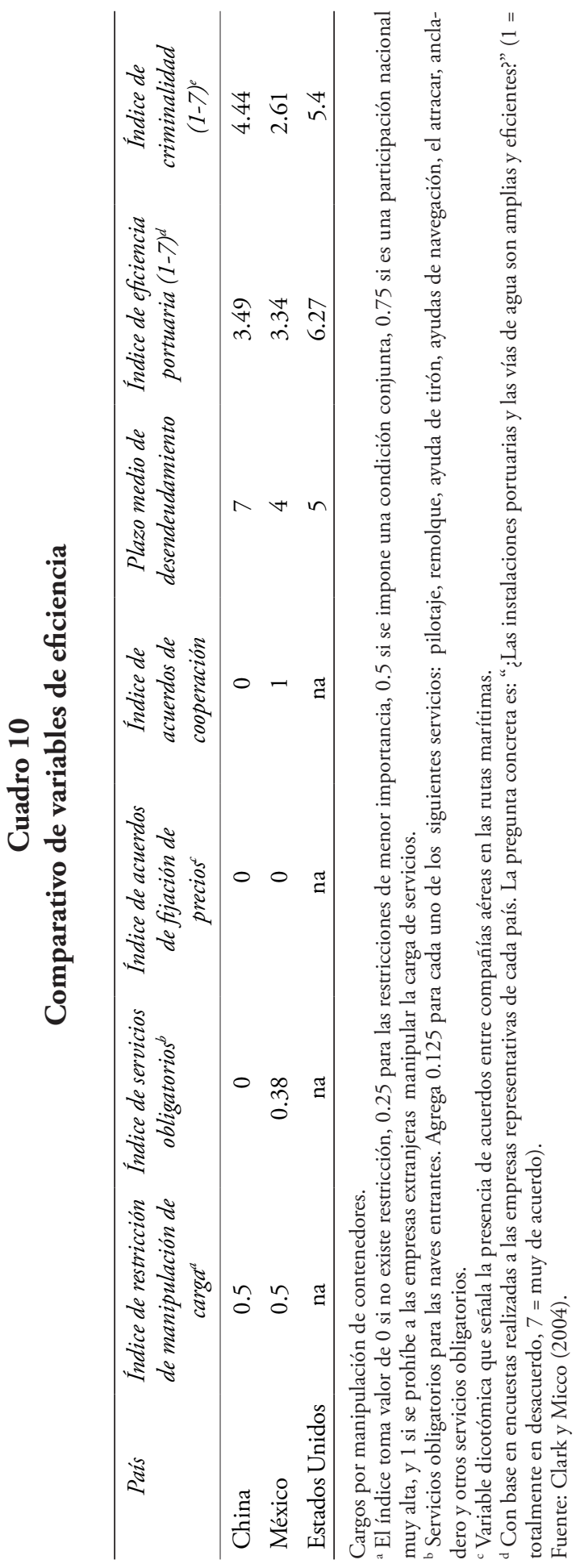




\section{Cuadro 11}

\section{Documentos, tiempo y costos de exportación en México y China}

\begin{tabular}{cccccc}
\hline Pais & $\begin{array}{c}\text { Documentos } \\
\text { para exportar } \\
\text { (número) }\end{array}$ & $\begin{array}{c}\text { Tiempo para } \\
\text { exportar } \\
\text { (dias) }\end{array}$ & $\begin{array}{c}\text { Costo de } \\
\text { exportación } \\
\text { (US\$ por } \\
\text { contenedor) }\end{array}$ & $\begin{array}{c}\text { Documentos } \\
\text { para } \\
\text { importar } \\
\text { (número) }\end{array}$ & $\begin{array}{c}\text { Tiempopara } \\
\text { importar } \\
\text { (dias) }\end{array}$ \\
\hline China & 7 & 21 & 500 & 5 & 24 \\
México & 5 & 14 & 1,472 & 5 & 17 \\
\hline
\end{tabular}

Fuente: Elaboración propia con base en datos del Banco Mundial (2010).

\section{Cuadro 12 \\ Ventajas para exportar e importar}

\begin{tabular}{lrrr}
\hline \multicolumn{1}{c}{ Indicador } & México & $\begin{array}{c}\text { América Latina } \\
\text { yel Caribe }\end{array}$ & $\begin{array}{c}\text { OCDE } \\
\text { promedio }\end{array}$ \\
\hline Documentos para exportar (número) & 5 & 6.8 & 4.3 \\
Tiempo para exportar (días) & 14 & 18.6 & 10.5 \\
Costo de exportación & 1,472 & $1,243.6$ & $1,089.7$ \\
(US\$ por contenedor) & & & \\
Documentos para importar (número) & 5 & 7.3 & 4.9 \\
Tiempo para importar (días) & 17 & 20.9 & 11.0 \\
Costo de importación & 1,780 & 1,481 & $1,145.9$ \\
(US\$ por contenedor) & & & \\
\hline
\end{tabular}

Fuente: Elaboración propia con base en World Economic Forum (2010). 


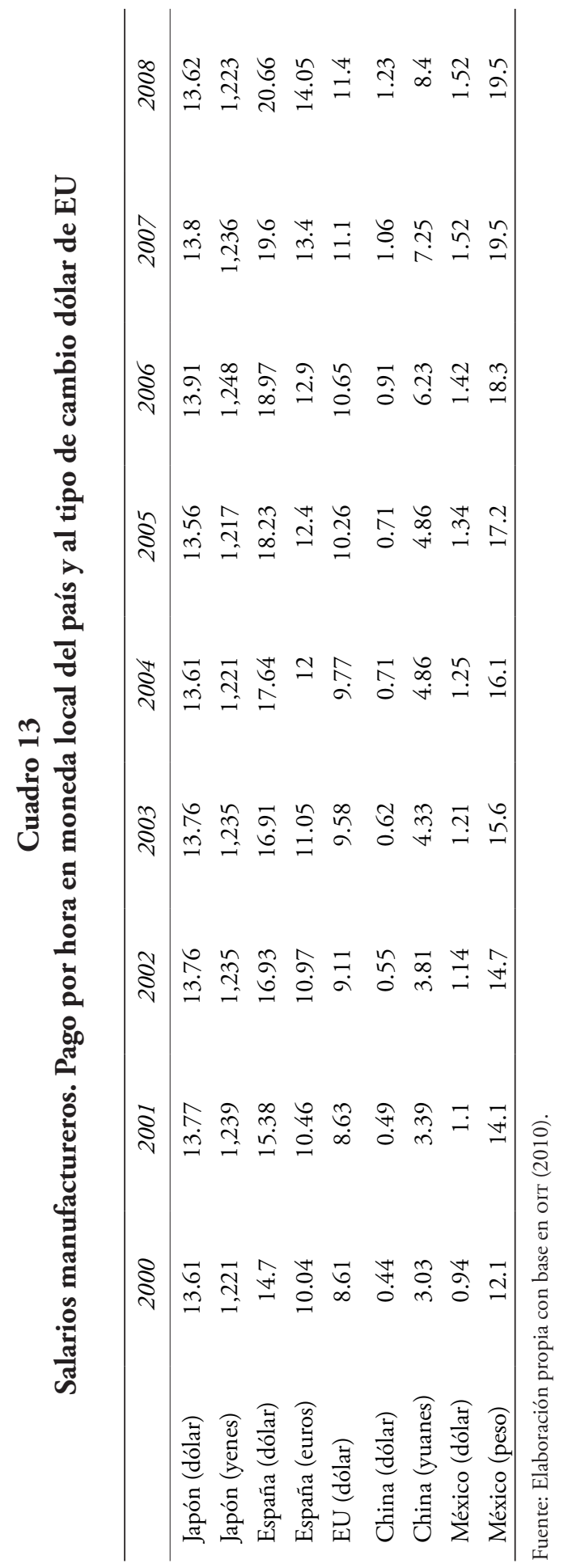




\section{Bibliografía}

BM (Banco Mundial) (2010), “Doing Business 2010”, <http://www. doingbusiness.org/documents/fullreport/2010/DB10-full-report. pdf $>, 1$ de enero de 2010.

Cárdenas, Hilda y Enrique Dussel (2007), "México y China en la cadena hilo-textil-confección en el mercado de EU", Comercio Exterior, 57 (7), Banco Nacional de Comercio Exterior, México, pp. 530545.

Chávez, Fernando y Lizbeth Leyva (2007), "México y China: competencia en el mercado de EU”, Comercio Exterior, 57 (11), Banco Nacional de Comercio Exterior, México, pp. 931-944.

Clark, Ximena David Dollar y Alejandro Micco (2004), "Port efficiency, maritime transport costs and bilateral trade", <http://www.nber. org/papers/w10353.pdf>, marzo de 2004.

Djankov, Simeon, Freund Caroline y Cong S. Pham (2008), “Trading Across Borders Methodology", International Finance Corporations, <http://www.doingbusiness.org/methodology/tradingacross-border $>, 3$ de febrero de 2010.

Duana, Dunae Ávila, Belida Ariana Reyes Mata, Edith Gutiérrez Martínez (2009), "La ventaja nacional de México y China", <http:// www.eumed.net/cursecon/ecolat/mx/2009/amm.htm>, $18 \mathrm{de}$ agosto de 2009.

Dussel, Enrique (2008), "Los costos de transporte en las exportaciones mexicanas", <http://www.dusselpeters.com/39.pdf>, 20 de agosto de 2008 .

Dussel Enrique y Xue Liu (2004), “Oportunidades y retos económicos de China para México y Centroamérica”, <http://www.dusselpeters.com/L633-parte1.pdf>, 27 de septiembre de 2004.

Dutta, Manoranjan (2005), China's industrial revolution and economic presence, World Scientific Books, Hackensack, NJ.

El Siglo de Torreón (2008), "Altos precios del transporte a favor de México sobre China”, <http://www.elsiglodetorreon.com.mx/noti- 
cia/354187.altos-precios-del-transporte-a-favor-de-mexic.html>, 29 de mayo.

Foreign Trade (2010), us Department of Commerce, <http://www.census. gov/foreign-trade/>, 1 de enero de 2010.

François, Joseph y Dean Spianger (2002), “Greater China’s Accession to the wto: Implications for International Trade/Production and for Hong Kong", <https:/www.gtap.agecon.purdue.edu/resources/ download/1037.pdf>, 5 de junio de 2002 .

García, Guadalupe (2009), "Estrategias corporativas y restructuración de las cadenas de proveeduría del vestido hacia Estados Unidos: el caso de la firma Levi Strauss \& Co", Estudios Fronterizos, 10 (20), Universidad Autónoma de Baja California, La Paz, pp. 103-128.

Harrigan James y Anthony Venables (2004), "Timeliness, trade and Agglomeration", <http://www.econ.hit-u.ac.jp/ - trade/2004/papers/venables.pdf>, 21 de septiembre de 2004 .

Herrera, Beethoven (2005), Globalización: el proceso real y financiero, Universidad de Colombia, Bogotá.

Hummels, David (2001), “Time as a trade barrier”, <http://www.krannert. purdue.edu/faculty/hummelsd/research/time3b.pdf>, 1 de julio de 2001 .

INEGI (Instituto Nacional de Geografía, Estadística e Informática) (2007), "Sistema Armonizado de Designación y Codificación de Mercancías”, INEgi, México.

Krugman, Paul (1991), "Increasing Returns and Economic Geography”, Journal of Political Economy, 99 (3), Universidad de Chicago, Chicago, pp. 483-499.

Lanchovichina, Elena y William Martin (2003), "Economic Impacts of China's Accession to the World Trade Organization”, <http://siteresources.worldbank.org/INTDEBTDEPT/Resources/4689801206974166 266/4833916-1206974192224/PRWP3053.pdf>, mayo de 2003. 
Labiano, Virginia y Romina Loray (2006), "China: desafíos y oportunidades para México", <http://www.caei.com.ar/es/programas/ asia/26.pdf>, 12 de octubre de 2006.

López-Córdoba, Ernesto, Alejandro Micco y Danielken Molina (2009), "Exportaciones latinoamericanas y chinas hacia el mercado estadounidense" en Javier Santiso (ed.), La mano invisible de China en América Latina, OCDE, París, pp. 123-148.

Martínez, Inmaculada y Jan Hoffmann (2007), "Costes de transporte y conectividad en el comercio internacional entre la Unión Europea y Latinoamérica", Economía. Información Comercial Española, 834, Ministerio de Industria, Turismo y Comercio, Madrid, pp. 45-59.

Nordas, Kyvik (2004), “The Global Textile and Clothing Industry post the Agreement on Textiles and Clothing", <http://www.wto.org/ english/res_e/booksp_e/ discussion_papers5_e.pdf>, 1 de julio de 2004.

Rodríguez, Carlos y Lizbeth Fernández (2007), “¿Deja China posibilidades a la industria textil mexicana?", Revista Copérnico, Iv (6), Universidad Nacional Experimental de Guayana, Guayana, pp. 5-14.

Sanjay, Kathuria, Will Martin y Anjali Bherdway (2001), "Implications for South Asian Countries of Abolishing the multifibre arrangement", <http://www-wds.worldbank. org/external/default/ WDS ContentServer/IW3P/IB/2002/01/17/000094946_011211051 8494/Rendered/PDF/multi0page.pdf>, noviembre de 2001.

OCDE (Organización para la Cooperación y el Desarrollo Económicos) (2002), "China in the world economy. The domestic policy challenges”, <http://www.oecd.org/dataoecd/45/57/2075272.pdf>, París, 30 de noviembre de 2009.

oCDE (Organización para la Cooperación y el Desarrollo Económicos) (2007), Economic Survey of Mexico, ocde, París.

OIT (Organización Internacional del Trabajo) (2009), "Resumen ejecutivo. Informe mundial sobre salarios 2008/09. Salarios mínimos y negociación colectiva: hacia una política salarial coherente", 
<http:/www.ilo.org/wcmsp5/groups/public/---dgreports/--dcomm/documents/publication/wcms_100795.pdf >, 31 de diciembre de 2009.

OIT (Organización Internacional del Trabajo) (2010), Estadísticas por tipo, <http://laborsta.ilo.org/>, 1 de enero de 2010.

omc (Organización Mundial de Comercio) (2009), "Estadísticas de comercio internacional 2009”, <http://stat.wto.org/Home/WSDBHome.aspx? Language=S $>$, enero de 2010 .

Quinliang, Gu (2004), "Desarrollo de la industria del vestido en China”, en Isabel Rueda Peiro et al. (coords.), La industria de la confección en México y China ante la globalización, Miguel Ángel Porrúa, México.

Vázquez, Patricia (2002), "La competencia china para las exportaciones de manufactura mexicana hacia EU en las dos últimas décadas", México y la Cuenca del Pacífico, 5 (15), Universidad de Guadalajara, Guadalajara, pp. 77-83.

World Economic Forum (2010), “The Global Competitiveness Report 2009-2010”, <http://www.weforum.org/pdf/GCR09/GCR20092010 fullreport.pdf>, enero de 2010.

Yang, Yongzheng (2003), "China's Integration into the World Economy: Implications for Developing Countries", <http://www.un.org/ esa/policy/link/presentations04/yyang.pdf>, diciembre de 2003.

Recibido: 24 de marzo de 2010. Reenviado: 6 de abril de 2010. Reenviado: 12 de julio de 2011. Aceptado: 25 de agosto de 2011.

Maximiliano Gracia-Hernández. Es doctor en economía internacional por la Universidad de Barcelona. Es miembro del Sistema Nacional de Investigadores, nivel I. Actualmente es profesor e investigador en El Colegio del Estado de Hidalgo y la Universidad La Salle, México. Sus líneas de investigación actuales son: industria textil, confección e integración económica. Entre sus publicaciones se encuentran: "Determinantes 
teórico-históricos en la localización de la industria textil-confección de Tlaxcala", Temas de Ciencia y Tecnología, 14 (40), Universidad Tecnológica de la Mixteca, Huajuapan de León, Oaxaca, pp. 13-22 (2010); "Análisis, resultado y perspectivas del Acuerdo de Asociación Económica México-Japón”, Economía Autónoma, II (4), Universidad Autónoma Latinoamericana, Medellín, pp. 86-115 (2009); "La industria del calzado en León, Guanajuato, México. Análisis a partir de las economías externas y de urbanización", Economía Autónoma, 3, Universidad Autónoma Latinoamericana, Medellín, pp. 15-32 (2009); "Efectos económicos de los criterios de convergencia en el proceso de inserción de Bulgaria y Rumania a la Unión Europea”, Economía, Sociedad y Territorio, IX (30), El Colegio Mexiquense, Zinacantepec, pp. 229-258 (2009). 